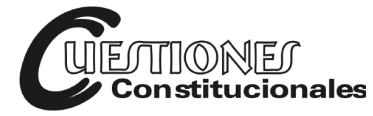

Revista Mexicana de Derecho Constitucional

Núm. 26, enero-junio 2012

\title{
APROXIMACIONES TEÓRICAS DE LA IGUALDAD EN LA NORMATIVA CONSTITUCIONAL ESPAÑOLA
}

\author{
THEORETICAL APPROACHES FOR EQUALITY \\ IN THE SPANISH CONSTITUTIONAL LAW
}

Aída Figueroa Bello*

\begin{abstract}
RESUMEN: Este trabajo constituye un análisis de la noción de igualdad, dando a conocer su tridimensionalidad en el marco de la teoría constitucional española, al ser considerada bajos tres conceptos: como principio, valor superior y derecho fundamental. Aunado a ello, centrándonos en las dos vertientes clásicas de la igualdad: formal y material o sustancial, ambas expresadas en los artículos constitucionales 14 y 9o., apartado 2o., respectivamente, dando a conocer algunas aproximaciones relativas a lo que ha supuesto la normativa adoptada en materia de igualdad de género en España, y particularmente en lo que se refiere a la Ley Orgánica $3 / 2007$, del 22 de marzo para la igualdad efectiva de Mujeres y Hombres, y el novedoso avance que ha supuesto en la legislación española, las sentencias del Tribunal Constitucional emitidas a raíz de la aprobación de la Ley 01/2004, del 28 de diciembre, de Medidas de Protección Integral contra la Violencia de Género, relativas al trato diferente entre hombres y mujeres en el ámbito penal, y finalmente, en las denominadas cuotas electorales, medidas de acción positiva destinadas a lograr la paridad democrática.
\end{abstract}

Palabras clave: Igualdad, tridimensionalidad, igualdad formal, igualdad material, igualdad de género.
ABSTRACT: This paper is an analysis of the notion of equality, revealing their three-dimensionality in the context of the Spanish constitutional theory, to be considered under three concepts: in principle, superior value and fundamental right. Added to this, focusing on the two sides classical equality: formal and material or substantial, both expressed in the constitutional articles 14 and 9o., 2o., respectively. And finally, looking at some notes on what has meant the rules adopted gender equality in Spain, particularly in regard to the Organic Law 3/2007 of 22 March for effective equality of women and men, and the new progress that has been implicated in the Spanish legislation, the Constitutional Court decision issued following the adoption of Law 01/2004 of 28 December on Integrated Protection Measures against Gender Violence, on the differential treatment between men and women in the criminal field, and finally, in the so-called electoral quotas, affirmative action measures designed to achieve parity democracy.

Descriptors: Equality, three-dimensionality, formal equality, substantive equality, gender equality.

*Profesora e investigadora en el Centro de Investigación de Tecnología Jurídica y Criminológica de la Universidad Autónoma de Nuevo León, México. Reconocimiento SNI-Conacyt, nivel 1, Perfil Promep. 


\section{INTRODUCCIÓN}

Este trabajo tiene como propósito principal dar a conocer algunas ideas y aproximaciones de la noción de igualdad desde la perspectiva teórica constitucional española, tomando como punto de partida el ordenamiento constitucional, dando a conocer en primer lugar, la tridimensionalidad de la igualdad, considerándola como: principio, valor superior y derecho fundamental. En segundo lugar nos referiremos a las dos vertientes de la igualdad: formal y material o sustancial, ambas expresadas en los artículos constitucionales 14 y 9o., apartado 2o., respectivamente, señalando sus características y peculiaridades. Finalmente en el último apartado nos dedicaremos a un breve análisis de cada una de estas dos líneas de la igualdad.

El interés temático del desarrollo de este trabajo consiste en el avance normativo que a nivel constitucional ha caracterizado a España, implementando diversas normativas que tienen como principal objetivo brindar congruencia a dos de los artículos integrados en su normativa constitucional, tratando de permear que los postulados teóricos coincidan con la realidad socio jurídica española.

No hay duda que la igualdad ha representado uno de los pilares básicos y fundamentales de todo Estado (de derecho, democrático y social, que se precie de serlo), tanto en el estudio dogmático-jurídico como en el pensamiento político de diversos doctrinarios a la que han depositado pleno interés, especialmente desde la teoría jurídica y política. Recordemos que incluso desde los griegos, la idea de igualdad, estaba sujeta a consideraciones un tanto lineales, a quienes se les aplicaba la igualdad a los iguales, y de manera inversa, a los desiguales, la desigualdad, de esta manera, justificando y legitimando la esclavitud, condición que representaba ni siquiera un asomo al elemento básico de todo persona, la dignidad humana.

Aunado al surgimiento del ideario igualitario, debemos hacer referencia obligada a lo que supuso la Revolución francesa ${ }^{1}$ como acontecimiento histórico que proclamaba Liberté, Fraternité, Egualité, trinomio en el que se

1 Reichardt, Rolf y Fusi Aizpurúa, Juan Pablo, La Revolución francesa y la cultura democrática: la sangre de la libertad, Madrid, Siglo XXI de España, 2002. García Ferrer, Juan José, "E. Burke: Reflexiones sobre la Revolución francesa”, en García San Miguel Rodríguez-Arango, Luis, Filosofía politica: las grandes obras, España, Dykinson, 2006, pp. 463-485. Barcellona Pietro, "Estado de derecho, igualdad formal y poder económico: apuntes sobre formalismo y orden económico", Anales de la Cátedra Francisco Suárez, núm. 29, 1989, pp. 63-96. 
agrupaban las exigencias filosófico políticas, representando el rompimiento y destrucción del denominado Ancien Regimen, marcando un parteaguas en la historia moderna. De ello, el punto de partida lo constituiría la Declaración de Derechos del Hombre y del Ciudadano, documento que plasmaría los lineamientos de una ideología liberal, con el triunfo del capitalismo frente al feudalismo, y que con posterioridad, a mitad del siglo XX, daría paso a otra, considerada bajo directrices democráticas y social, en donde el Estado fungiría como principal actor en las áreas socioeconómicas, estableciendo por un lado, un marco de libertades, pero por otro, también, suprimiendo todos aquellos obstáculos que implicasen desigualdades reales, logrando así una igualdad efectiva y real en la sociedad.

Pues bien, y dado que al concepto de igualdad se le ha considerado como un valor igualmente supremo, intrínseco al ser humano, ${ }^{2}$ a la esencia humana y a su dignidad como tal, esto es, a la igualdad esencial de todos los seres humanos, pudiendo así afirmar que dentro del Estado de derecho, resultaría ser un elemento insoslayable para concebirlo.

En este mismo sentido, conviene hacer algunas apreciaciones respecto a la idea de igualdad con relación a la identidad y a la semejanza. Entre la gran diversidad existente entre los seres humanos, prevalecen ciertas características y peculiaridades entre nosotros que nos identifican y nos muestran con determinadas semejanzas. Es precisamente este trecho de similitud $^{3}$, de congruencia, de igualdad, esta dimensión de semejanza que nos permite identificarnos y que obedece a que los seres humanos debamos ser iguales, debamos ser tratados en igualdad, ${ }^{4}$ de forma prescripti-

2 Como acontecimiento histórico que proclamaba el derecho de igualdad del ciudadano ante la ley, igualdad de sufragio, descartando toda posibilidad de acceder al poder del Estado mediante un derecho innato, sino planteando una garantía de igualdad a todo hombre para acceder a los cargos públicos, así como también una igualdad impositiva en función de la riqueza. Para un estudio de la evolución histórica de este principio y la proyección universal que supuso la Revolución francesa consúltese, García de Enterría, Eduardo, Revolución francesa y administración contemporánea, Madrid, Alianza Editorial, 1994.

3 Rubio Llorente, Francisco, "La igualdad en la jurisprudencia del Tribunal Constitucional. Introducción”, El principio de igualdad en la Constitución española, XI Jornadas de Estudio, Madrid, Ministerio de Justicia, Secretaría General Técnica, 1991, vol. I, pp. 681- 709, especialmente, pp. 686-688.

4 Laporta, Francisco J., "El principio de igualdad. Introducción a su análisis", Siste$m a$, núm. 67, julio de 1985, p. 14. Del mismo autor, véase, "Problemas de la igualdad", en Valcárcel, Amelia (ed.), El concepto de igualdad, Madrid, Pablo Iglesias, 1994, p. 66 
vamente normativa, ${ }^{5} \sin$ atender a los aspectos que nos hacen diferentes entre sí, igualdad que se le ha denominado igualdad como equiparación o indiferenciación. Por consiguiente, la igualdad conlleva un carácter relaciona $1^{6}$ entre dos o más personas, objetos o situaciones, y los cuales deben contar con determinados atributos o rasgos que impliquen su carácter comparativo, conocido en la doctrina constitucional española como términos de la comparación, con lo cual se podría plantear su punto de igualdad, y por ende, el elemento o la pluralidad de elementos que supongan una diferencia, componente necesario para el juicio de igualdad; cuestión diversa si no existiesen los elementos de diferencia, puesto que en ese supuesto hablaríamos de identidad, más no de igualdad.

De ahí que el concepto de igualdad es siempre relativo, atendiendo a la esencia misma de su concepto, esto es, al carácter diferencial que engloba el atributo intrínseco de la noción de igualdad, y que a primera vista, podría traducirse en una contradicción, principalmente en lo que se refiere a la necesidad de elementos de comparación que impliquen la existencia de la relación de igualdad, esto es, al grado que el propio derecho pueda considerar iguales a personas por demás diferentes, con base a la norma que éste mismo dispone como elemento de igualdad entre ellas. Uno de los atributos de la igualdad consiste en homogeneizar a los individuos frente a la normativa, al grado de ignorar aquellas características o detalles que motivan su distinción de hecho, esto es, tiende a hacer más iguales a esos individuos para efectos de las consecuencias normativas, ${ }^{7}$ al determinar la idea de igualdad, razonable y no arbitrariamente, qué grado de desigualdad jurídica de trato entre dos o más sujetos es tolerable. ${ }^{8}$

Ahora bien, y de acuerdo al principio general de igualdad en el ordenamiento constitucional español, todos los hombres deben ser tratados en igualdad, salvo que el trato desigual exponga razones que lo justifiquen. Por

y ss. Calsamiglia, Albert, Sobre el principio de igualdad, en Muguerza, J. et. al., El fundamento de los derechos humanos, Madrid, Debate, 1989, pp. 97 y ss.

5 Calsamiglia, Albert, op. cit., p. 98. Laporta, Francisco J., op. cit., p. 4. Pérez Luño, Antonio Enrique, "Sobre la igualdad en la Constitución española", Anuario de Filosofía del Derecho, t. IV, 1987, p. 141.

6 Westen, P., "The Empty Idea of Equality”, Harvard Law Review, núm. 95, 1982, p. 537.

7 Laporta, Francisco J., op. cit., p. 14.

8 Rey Martínez, Fernando, "El derecho fundamental a no ser discriminado por razón de sexo", La discriminación por razón de sexo tras 25 años de la Constitución Española, Madrid, Consejo General del Poder Judicial, 2004, p. 30. 
tanto, partiendo de estas premisas, podemos decir que, y aún de acuerdo a la ley, existirían tratos iguales y desiguales completamente lícitos, en el que el primero, al suponer un trato igual, sería válido y lícito, simplemente si no admite ninguna diferencia, y en el segundo, en el tratamiento desigual constituiría un ilícito si no presenta una razón que lo justifique.

Atendiendo a ello, entonces podemos afirmar que ¿la igualdad se configura como un ideal ${ }^{9}$ a alcanzar, puesto que aún en la ley se determinan supuestos justificativos y razonables para la desigualdad, justificada y razonable? lo que en términos filosóficos Norberto Bobbio afirma como la deseabilidad de la igualdad..$^{10}$ La cuestión a determinar consistirá en encuadrar las causas o razones justificativas para otorgar un trato igual o bien, desigual, y esto se llevará a cabo mediante el denominado test de razonabilidad de la igualdad/desigualdad, considerado como el criterio para determinar la observancia de la igualdad en la ley, y en el que por tanto, el trato desigual tendría la carga de argumentación, o mejor dicho, de justificación.

Es justamente este postulado establecido en la norma constitucional española, una igualdad formal absoluta, ${ }^{11}$ lo que dista de la igualdad fáctica real, la vieja regla: del deber ser y del ser. De ahí que nos interese destacar que no se toma en consideración los rasgos diferentes entre los hombres, sino sólo y de manera positiva, el elemento de igualdad, aquella generalización normativa-legislativa que otorga equiparación, igualdad —igualdad formal - a los seres humanos. Por consiguiente, podemos afirmar que la igualdad constituye un valor analizado tradicionalmente bajo estos dos rubros: como igualdad formal prescriptiva y como igualdad material o sustancial.

9 Pérez Luño, Antonio Enrique, Dimensiones de la igualdad, 2a. ed., Madrid, Dylinson, 2007, p. 16.

10 Bobbio, Norberto, Igualdad y libertad, Barcelona, Paidós, 1993, p. 88.

11 Obsérvese que empleamos el término igualdad formal absoluta referido exclusivamente al ámbito normativo, a lo establecido por la ley, pues de lo contrario, si consideramos "que la única igualdad imaginable en términos absolutos entre dos entidades es la que puede predicarse de todos sus elementos componentes y de todas las propiedades que a cada una de ellas corresponden, habrá que deducir también, que concebida en estos términos, la igualdad no puede existir." Consúltese Ara Pinilla, I., "Reflexiones sobre el significado del principio constitucional de igualdad", en García San Miguel, L., El principio de igualdad, Madrid, Dykinson, 2000, p. 202. 


\section{LA TRIDIMENSIONALIDAD DE LA IGUALDAD}

El concepto de igualdad se ha englobado desde diversas manifestaciones filosóficas, jurídicas, políticas, éticas, económicas. Asimismo, en los diferentes sistemas jurídicos goza de diversas apreciaciones y valoraciones teóricas en el ámbito constitucional. Así, por ejemplo, en el caso italiano (derecho individual y social, ligada a la dignidad social, artículo 3o., constitucional), el ámbito francés (prevalece la igualdad ante la ley, artículo 1o., constitucional), el caso alemán (igualdad ante la ley, en su numeral 3o., de su ley fundamental), el caso portugués (como principio ligándolo a la dignidad social y la igualdad ante la ley, artículo 11 constitucional), o bien, el Convenio Europeo de Derechos Humanos en su artículo 14 contempla la igualdad sólo como un valor y como un principio, integrando su naturaleza en una garantía de no discriminación en el goce de los derechos y libertades reconocidos por este instrumento internacional, garantía ajustada a los demás derechos establecidos en este Convenio.

Pues bien, en la dimensión constitucional española, la idea de igualdad se recoge desde tres categorías: ${ }^{12}$ como valor supremo ${ }^{13}$ — dispuesto en el

12 Freixes Sanjuán, Teresa y Remotti Carbonell, José Carlos, "Los valores y principios en la interpretación constitucional", Revista Española de Derecho Constitucional, año 12, núm. 35, mayo-agosto de 1992, pp. 97- 109. Sánchez González, Santiago, "En torno a la igualdad y a la desigualdad", en Sánchez González, Santiago (coord.), En torno a la igualdad y a la desigualdad, Madrid, Dykinson, 2009, pp. 15-28, en particular, pp. 18-23.

13 Consúltese, al respecto, Suárez Pertierra, Gustavo, “Artículo 14”, en Alzaga Villamil, Oscar (dir.), Comentarios a las Leyes Politicas. Constitución Española de 1978, Editorial Revista de Derecho Privado, 1984, t. II, pp. 277-293, quien considera al principio de igualdad bajo diferentes acepciones, como un valor superior de no sólo el ordenamiento constitucional español, sino de todo el ordenamiento jurídico del Estado español; como condicionante del Estado social de derecho; como norma programática dirigida a informar la actividad de todos los poderes públicos; como derecho jurisdiccional considerado como derecho objeto de protección y por tanto, como derecho recurrible, concibiéndola como un auténtico derecho fundamental con protección especial. En este mismo sentido véase, Figueruelo Burrieza, Ángela, "El discurso jurídico: la mujer en la Constitución española”, en Figueruelo Burrieza, Ángela y López de la Vieja, Teresa et. al. (eds.), Las mujeres en la Constitución europea. Estudios multidisciplinares de género, Salamanca, Ediciones Universidad de Salamanca-Centro de Estudios de la Mujer, 2005, colección Aquilafuente, p. 21, quien la considera como un valor del ordenamiento jurídico, así como condición ideal de la vida social que debe perseguirse por los poderes públicos. Consúltese también, Parejo Alfonso, Luciano, Constitución y valores del ordenamiento, Madrid, Centro de Estudios Ramón Areces, 1990, pp. 117-149. 
artículo 1o., parágrafo 10.- , como principio ${ }^{14}$ — expresado en los artículos 9o., parágrafo 20., y $14-$, y como derecho fundamental ${ }^{15}$ - establecido en el artículo 14-y en otros más en los que se alude a diversos derechos, como por ejemplo, el derecho al acceso y permanencia en los cargos y funciones públicas, el derecho de igualdad en la contribución de los gastos públicos, entre otros. De ahí que bajo esas tres acepciones de la igualdad, se ha aseverado que ésta implica a su vez, tres tipos de discursos: el discurso axiológico — igualdad como valor —; el discurso normativo ${ }^{16}$ —igualdad como principio-, y por último, el discurso postulativo ${ }^{17}$ —igualdad como derecho fundamental-, autónomo. ${ }^{18}$

A este respecto y en relación a las tres dimensiones que el ordenamiento constitucional español considera la igualdad, debemos señalar que es considerada como un valor jurídico superior, junto con la libertad, la justicia y el pluralismo político, valores que representan la base fundamental de una cultura jurídica, insertados en un orden político como pilares indispensables para el desarrollo y convivencia en un Estado social de derecho, advirtiendo de esta manera la estrecha relación que existe entre moral y derecho, constituyendo una amalgama entre estos dos ámbitos. ${ }^{19} \mathrm{~A}$ la igualdad se le

14 Véase Freixes Sanjuán, Teresa, op. cit., pp. 97-101. Por su parte, Suay-Rincón, José, El principio de igualdad en la justicia constitucional, Madrid, Instituto de Estudios de Administración Local, 1985, p. 152, asevera que la igualdad constituye un valor supremo y un principio. En esta misma postura se pronuncia Martínez-García, J. L., "Justicia e igualdad en Luhmann", Anuario de Filosofía del Derecho, núm. 4, 1987, pp. 42 y ss.

15 Castedo Álvarez, F., "La Constitución como fuente de derechos", en Angulo Rodríguez, Edmundo et. al., La Constitución española y las fuentes del derecho, Madrid, Dirección General de lo Contencioso del Estado, 1980; Castro Cid., B., "Derechos humanos y Constitución", Revista de Estudios Políticos, núm. 18, Centro de Estudios Constitucionales, 1980; Rubio Llorente, F. et. al., Derechos fundamentales y principios constitucionales. Doctrina jurisprudencial, Barcelona, Ariel, 1995; Cfr. Puy, Francisco, "El derecho a la igualdad en la Constitución española", El principio de igualdad en la Constitución española, XI Jornadas de Estudio, Madrid, Ministerio de Justicia, Secretaría General Técnica, 1991, vol. I, p. 152. Blázquez J., Igualdad, dignidad y libertad, Navarra, Universidad Pública de Navarra, 1998.

${ }^{16} C f r$., Basile, S., "Los «valores superiores», los principios fundamentales y los derechos y libertades públicas”, en Predieri, A. y García de Enterría, E. (eds.) La Constitución española de 1978, Madrid, Civitas, 1980, pp. 253-205, en particular, p. 277.

${ }_{17}$ Puy, Francisco, op. cit., pp. 133-155.

18 Cfr. Ibidem, p. 135.

19 Peces-Barba, Gregorio, Los valores superiores, Madrid, Tecnos, 1984, pp. 74-114; del mismo autor, "Seguridad jurídica y solidaridad como valores de la Constitución española" Funciones y fines del derecho, Murcia, Universidad de Murcia, 1992; Prieto, Luis, 
ha considerado como sinónimo de indiferencia o equivalencia, poniendo de manifiesto el rasgo de abstracción de las normas, al tratar de equiparar situaciones, es así como la igualdad, de manera paradójica implica indiferencia manteniendo una diferencia, constituyendo así el principio de igualdad como un mediador de complejidad, que permite considerar diferencias como causas justas y razonadas mediante la fundamentación, puesto que sólo la desigualdad debe ser fundamentada. ${ }^{20}$

La igualdad como valor ${ }^{21}$ conforma un conjunto, un todo junto con otros valores, como la libertad, la solidaridad y la seguridad. De ahí que podamos expresar que la igualdad no puede considerarse en términos abstractos, esto es, que en todo supuesto estará correlacionada con situaciones concretas y específicas que determinarán su punto en comparación. Si bien es cierto que desde el punto de vista constitucional, la igualdad refleja una tridimensionalidad, desde una visión teórica constitucional, la noción de igualdad en el caso español, alude a una multidimensionalidad, dado que se le ha considerado desde diversas acepciones de acuerdo al ámbito en el que se analice. Por ejemplo, desde su ámbito de acción como una exigencia de trato rigurosamente igual, traduciéndose en un trato paritario, sin tener en consideración todo tipo de diferencia que pueda existir. Un segundo plano, como una necesidad de adecuar la acción a las diferencias existentes, es decir, tratar lo igual como igual, y lo diferente como diferente, que implicaría por tanto, un trato igual.

La igualdad se consagra de manera genérica en el artículo 1o., parágrafo 1o., de la Constitución española, ${ }^{22}$ con el carácter de valor superior, otorgándole un papel central en el ordenamiento jurídico español, disposición constitucional que contempla su pleno desarrollo en sus dos dimensiones

“Los valores superiores del ordenamiento jurídico y el Tribunal Constitucional”, Poder Judicial, núm. 11, junio de 1984; Del Rey Guanter, S., "La aplicación de los valores superiores de la Constitución española en el derecho del trabajo", La Ley, 1988-I.

20 Martínez, Jesús Ignacio, "El principio de igualdad y la producción de diferencias en el derecho", El principio de igualdad en la Constitución española, XI Jornadas de Estudio, Madrid, Ministerio de Justicia, Secretaría General Técnica, 1991, vol. I, pp. 540561, en especial pp. 541-542.

21 Peces-Barba, Gregorio, op. cit., pp. 148-163. Pérez Luño, Antonio Enrique, op. cit., p. 141 .

22 Es mediante el contenido de este artículo constitucional que se puede leer la concepción de España como un Estado social y democrático de derecho, expresando su ordenamiento jurídico mediante valores superiores, tales como la libertad, la dignidad, la igualdad y el pluralismo político. Peces-Barba, Gregorio, op. cit., pp. 57-74. 
en el artículo 9o., apartado 2o., y el artículo 14: la igualdad sustancial y la igualdad formal, respectivamente.

\section{LA IGUALDAD FORMAL (ARTÍCULO 14 CONSTITUCIONAL)}

Dentro del ámbito doctrinario ${ }^{23}$ y jurisprudencial ${ }^{24}$ se ha denominado a la igualdad como, por un lado, otorgar consecuencias jurídicas iguales a supuestos de hecho iguales, y por otro, tratar de manera desigual a supuestos desiguales, este ha sido la máxima clásica de igualdad. El principio de igualdad jurídica, de igualdad frente a la ley (igualdad formal) de ser tratados en iguales condiciones y circunstancias ha sido uno de los firmes ideales y postulados en todos los instrumentos jurídicos que expresan derechos y en toda sociedad jurídico política que se precie defensora de las libertades regidas por el Estado de derecho. ${ }^{25}$ La igualdad ha sido la bandera del Es-

${ }^{23}$ Martínez, Jesús Ignacio, op. cit., pp. 541-542. Rubio Llorente, Francisco, "Igualdad", en Aragón Reyes, Manuel (coord.), Temas básicos de derecho constitucional, Madrid, Civitas, 2001, t. III, pp. 136-141. Gálvez, Javier, “Artículo 14", en Garrido Falla, Fernando et. al., Comentarios a la Constitución, Madrid, Civitas, 1985, pp. 254-265. Figueruelo Burrieza, Ángela, op. cit., p. 21, quien expresa que un igual trato significa "tratar igual las situaciones iguales, permitiendo diferencias de trato para situaciones diferentes", diferencias condicionadas a ser justificadas y razonables, atendiendo al criterio de razonabilidad. López Rodó, Laureano, "El principio de igualdad en la jurisprudencia del Tribunal Constitucional", Revista de Administración Pública, vol. I, núm. 100, Centro de Estudios Constitucionales, Madrid, enero-diciembre de 1983, pp. 331-345, también apunta que el concepto de igualdad implica un derecho subjetivo de obtener un trato igual.

24 De esta manera se ha expresado el Tribunal Constitucional, al referirse que no toda igualdad jurídica implica una igualdad material o efectiva, así podemos citar Sentencia TC 49/1982, del 14 de julio de 1982, mediante la cual el Tribunal Constitucional considera a la igualdad como un derecho fundamental, estableciendo que la igualdad formal en la aplicación de la ley que consagra el artículo 14 de la Constitución española se refiere a que "supuestos de hecho iguales deben serle aplicadas unas consecuencias jurídicas que le sean iguales también y que para introducir diferencias entre los supuestos de hecho tiene que existir una suficiente justificación de tal diferencia, que aparezca al mismo tiempo como fundada y razonable, de acuerdo con criterios y juicios de valor generalmente aceptados".

25 En este sentido, Gálvez, Javier, op. cit., pp. 255-258, alude a la cuestión axiológica del principio de igualdad, poniendo de manifiesto que ya no sólo debe referirse al ámbito de la realidad, sino más allá, al aspecto ético del propio ideal del hombre, expresando que el principio de igualdad integra dos funciones, considerado como principio constitucional, y como principio general del derecho, al que se encuentra supeditada la aplicación del principio de libertad. En este mismo sentido, Alzaga Villaamil, Oscar, Comentario 
tado liberal, junto con la libertad y fraternidad, ideales representativos en la Revolución francesa en el siglo XVIII. Ha representado una conquista del Estado liberal que representó el fin de una etapa histórica caracterizada por la arbitrariedad y la desigualdad socioeconómica desarrollada durante la Edad Media.

En tanto que principio estricto y derecho fundamental, la igualdad representa una de las categorías jurídicas fundamentales de la filosofía jurídica. ${ }^{26} \mathrm{Y}$ al considerarla como principio, se establece en el artículo 14 del ordenamiento constitucional español, consagrándola como principio formal. De esta manera dispone que, los españoles son iguales ante la ley sin que pueda prevalecer discriminación alguna por razón de raza, sexo, religión, opinión o cualquier otra condición o circunstancia personal o social, citando una lista meramente enunciativa con causas específicas por las que se prohíbe todo trato de discriminación, disponiendo una cláusula abierta en la que se engloba todo aquella circunstancia bajo la cual se presentaría un tratamiento discriminatorio, ${ }^{27}$ con la finalidad de no dejar fuera ninguna otra causa o razón que no se señale de manera expresa.

sistemático a la Constitución española de 1978, Madrid, Ediciones del Foro, 1979, pp. 181-183, alude al principio de igualdad ante la ley como uno de los pilares de la Constitución española, y por tanto, como un derecho básico de todo ciudadano, afirmando que por ejemplo, los títulos nobiliarios concedidos a determinados personajes refieren a un reconocimiento que bajo ningún supuesto implican algún privilegio jurídico.

26 En este sentido, consúltese Prieto, Luis, Sobre principios y normas. Problemas del razonamiento jurídico, Madrid, Centro de Estudios Constitucionales, 1992, del mismo autor, "La doctrina de los principios generales del derecho y la distinción entre principios y reglas”, en Betegón, J. et. al., Lecciones de teoría del derecho, Madrid, McGraw-Hill, 1977; Rodríguez Toubes, J., Principios, fines y derechos fundamentales, Dykinson, Madrid, 2000; Gordillo, A., Ley, principios generales y Constitución. Apuntes para una relectura, desde la Constitución, desde la teoría de las fuentes del derecho, Madrid, Centro de Estudios Ramón Areces, 1990.

27 Por su parte nos señala Garrorena, Ángel, El Estado español como Estado social $y$ democrático de derecho, Madrid, Tecnos, 1987, p. 51 que lo esencial del principio de igualdad consagrado en el artículo 14 constitucional no implica no diferenciación, sino más bien, no discriminación, dado que el propio Tribunal Constitucional faculta al legislador para establecer normas que impliquen un trato desigual, condicionado a que exista una causa justa y razonable. En este mismo sentido véase, Ruíz Vadillo, Enrique, "El principio de igualdad en la Constitución española", El principio de igualdad en la Constitución española, XI Jornadas de Estudio, Madrid, Ministerio de Justicia, Secretaría General Técnica, 1991, vol. I, pp. 1547-1560, en particular, p. 1550, quien realiza un estudio del principio de igualdad en el ámbito punitivo, aseverando que el numeral 14 
Ahora bien, situándonos en el ámbito constitucional español, el numeral 14 se integra por dos partes: primero, enuncia la cláusula general de igualdad, ${ }^{28}$ en su segunda parte, expresa el principio de no discriminación, mediante un enunciado antidiscriminatorio, y concluye con la enunciación abierta respecto a las condiciones o circunstancias por las cuales se trate diferencial o discriminadamente a una persona.

Por consiguiente, el artículo 14, en su segundo inciso establece la cláusula general relativa al derecho a no ser discriminado por razones específicas (por razón de nacimiento, raza, sexo, religión, opinión o cualquier otro aspecto personal o socialmente considerado) el derecho a no ser discriminado infundadamente, con independencia de los rasgos o diferencias que cada español posea, es decir, al valor de todas las personas a ser tratadas con igualdad y sin diferencias, y por consiguiente constituirá una conducta discriminatoria cuando esta sea injusta o irrazonable. En este sentido, resulta oportuno señalar que el Tribunal Constitucional español ha manifestado en su jurisprudencia que la discriminación constituye una vulneración, una violación al principio general de igualdad, esto es, una desigualdad desprovista de justificación objetiva y razonable. ${ }^{29}$

constitucional prohíbe la desigualdad de tratamiento legal injustificado que carezca de causa justa y razonable.

28 Arozamena Sierra, Jerónimo, "Principio de igualdad y derechos fundamentales", en Valdés Dal-Re, Fernando, El principio de igualdad en la Constitución española, XI Jornadas de Estudio, Madrid, Ministerio de Justicia, Secretaría General Técnica, 1991, vol. I, p. 420.

29 Así, por ejemplo, se expresa en estos términos en las sentencias: Sentencia TC 22/81; del 2 de julio, aquí el Tribunal Constitucional declara la inconstitucionalidad de la disposición adicional quinta del Estatuto de los Trabajadores, interpretada como norma que establece la incapacitación para trabajar a los sesenta y nueve años y de forma directa e incondicionada la extinción de la relación laboral a esa edad; Sentencia TC 42/81 de 22 de diciembre, respecto a la violación del principio de igualdad consagrado en el artículo 14 de la Constitución española, relacionada con el artículo 23, apartado 2o. constitucional, relativo al acceso a los cargos y funciones públicas, aquí el Tribunal Constitucional declara la inconstitucionalidad del artículo 13., apartado 2o., y de la disposición transitoria segunda, número uno, de la Ley de la Generalidad de Cataluña número 3/1981, del 22 de abril, de Bibliotecas, por la que no exige el título correspondiente a un nivel, o ciclo dentro de tal nivel, o especialidad, sino la titulación de una determinada Escuela, la de Bibliología de Barcelona; Sentencia TC 75/83, del 3 de agosto, asunto relativo a la inconstitucionalidad de la Ley especial para el municipio de Barcelona, que condicionaba, para participar en un concurso para optar a la plaza de Interventor de Fondos del Ayuntamiento de Barcelona, no rebasar la edad de sesenta años, señalando que "sólo le resulta posible al legislador, en adecuada opción legislativa, establecer para los ciudadanos un 
Este principio de igualdad constituye uno de los pilares esenciales del sistema jurídico constitucional español, y desde la óptica jurisprudencial, se visualiza bajo dos perspectivas: la igualdad en la ley, y la igualdad en la aplicación de la ley. Esta primera perspectiva del principio general de igualdad es referida fundamentalmente a la obligación que tiene el legislador de garantizar un trato igual a los ciudadanos, con la prohibición de emitir normas o actos discriminatorios, esto es, la igualdad conlleva un límite al legislador para evitar que éste emita normas que impliquen tratamientos discriminatorios, emitiendo normas jurídicas generales ${ }^{30}$ y abstractas dirigidas a todos los ciudadanos y aplicables a ellos de manera idéntica.

Dicho esto, habrá que reconocer que la generalidad constituye una garantía de la igualdad, no obstante ello, también la ley permite establecer diferencias legítimas basadas en razones justificativas, y por consiguiente una conducta o trato discriminatorio será considerado como tal cuando carezca de fundamento jurídicamente considerado, o utilizando el término que emplea el Tribunal Constitucional español, con justificación objetiva y razonable. ${ }^{31}$

Por lo que se refiere a la segunda vertiente de este principio, la igualdad en la aplicación de la ley alude al tratamiento igualitario en la aplicación de las normas, prohibiendo la emisión de decisiones jurisdiccionales

trato diferenciado cuando tenga que resolver situaciones diferenciadas fácticamente con mayor o suficiente intensidad que requieren en su solución por su mismo contenido una decisión distinta, pero a tal fin resulta indispensable que exista una justificación objetiva y razonable, de acuerdo con criterios y juicios de valor generalmente aceptados, cuya exigencia deba aplicarse en relación con la finalidad y efectos de la medida considerada, debiendo estar presente por ello una razonable relación de proporcionalidad entre los medios empleados y la finalidad perseguida y dejando, en definitiva, al legislador con carácter general la apreciación de situaciones distintas que sea procedente diferenciar y tratar desigualmente, siempre que su acuerdo no vaya contra los derechos y libertades protegidos en los artículos 53, apartado 1o., y 9o., apartado 3o., de la Constitución ni sea irrazonada", declarándose que no ha lugar a considerar la inconstitucionalidad de esta Ley especial; Sentencia TC 31/84, del 7 de marzo, este asunto también es relativo a la edad, considerada como dato objetivo respecto a los trabajadores menores para la fijación de diferenciación salarial.

30 Laporta, Francisco J., op. cit., p. 10.

31 El Tribunal Constitucional español acogió esta línea de la jurisprudencia del Tribunal Europeo de Derechos Humanos, a través de la cual se ha establecido que una desigualdad debe perseguir objetivos constitucionalmente legítimos, cuya justificación debe ser razonable y objetiva. Véase Garrorena Ángel, op. cit., pp. 52-55, quien alude al alto nivel de subjetividad que supone el identificar cuándo estamos en un supuesto de causa justa y razonable, esto es, el juicio de razonabilidad. 
discriminatorias y arbitrarias, esto es, la aplicación del derecho a supuestos de hecho idénticos emitiendo resoluciones jurídicas igualmente idénticas, sin embargo, debemos aclarar que la aplicación del derecho por la autoridad jurisdiccional no resulta ser de forma mecánica, ${ }^{32}$ sino todo lo contrario, pues se le brinda a quien aplica la ley, un cierto margen de discrecionalidad, tal es esta situación que en no pocas ocasiones se emiten diversas decisiones judiciales a supuestos idénticos.

Ahora bien, la igualdad en la aplicación de la ley confluye con el principio constitucional de independencia judicial, a través del cual cada juez se encuentra facultado para emitir sus decisiones judiciales suficientemente fundamentadas y razonadas, aún sin estar obligado a sujetarse al precedente. ${ }^{33}$ Todo esto supone sin lugar a dudas, que la igualdad en la aplicación de la ley consiste en que los órganos judiciales no emitan decisiones judiciales arbitrarias, esto es, que en su actuar, en la interpretación y aplicación de la ley, no se incurra en desigualdades arbitrarias e injustificadas.

Podemos afirmar pues, que la igualdad en la aplicación de la ley corresponde a la igual aplicación de la ley a todos aquellos que se encuentren en los mismos supuestos de hecho, pero más aún, al proceder del órgano judicial libre de arbitrariedad y falta de motivación, quien tendría la facultad de cambiar de criterio, de acuerdo al principio de independencia y autonomía judicial, siempre y cuando sea de forma debidamente motivada y por tanto, no arbitraria, y lo que implicaría la igualdad en la aplicación de la ley sería la garantía de motivación de los pronunciamientos judiciales ${ }^{34}$ como elemento del derecho de tutela judicial efectiva consagrada en el ar-

32 Así quedó expresado por el Tribunal Constitucional español en Sentencia TC $78 / 84$, del 9 de julio, declarando que la igualdad de trato no puede significar una operación maquinal o automática de los órganos jurisdiccionales en la interpretación del derecho.

33 Véase al respecto la bibliografía relacionada al tema: Roca Trías, E., “Jurisprudencia, precedente y principio de igualdad”, Revista Jurídica de Cataluña, 1986; Requejo, J. L., "Juridicidad, precedente y jurisprudencia", Revista Española de Derecho Constitucional, núm. 29, mayo-agosto de 1990; Ollero, A., Igualdad en la aplicación de la ley y precedente judicial, Madrid, Centro de Estudios Constitucionales, 1989; Gastón Abellán, M., La técnica del precedente y la argumentación racional, Madrid, Tecnos, 1993; Jaén Vallejo, M., "El principio de igualdad en la aplicación de la ley por los órganos jurisdiccionales en la jurisprudencia del TC", Boletín del Colegio de Abogados de Madrid, 1987.

34 Sin embargo, el Tribunal Constitucional se ha pronunciado al respecto en Sentencia TC 142/85, del 23 de octubre, al afirmar que no toda ausencia de motivación expresa, produce una desigualdad inconstitucional, por no razonada y arbitraria, sino tan sólo aquélla en la que resulta patente que la diferencia de trato no obedece a una deliberada 
tículo 24, parágrafo 1o., de la Constitución española. Finalmente, podemos considerar la igualdad en la aplicación de la ley ya no sólo en el ámbito de la Administración gubernamental, sino también referida a la aplicación judicial de la ley.

\section{LA IGUALDAD MATERIAL Y EL ARTÍCULO 9O., PARÁGRAFO 20.}

Desde el plano del derecho comparado, ${ }^{35}$ una de las Constituciones que ha ejercido una importante influencia en la Constitución española de 1978, ha sido la Constitución italiana de 1947, particularmente en lo relativo al artículo 3o., parágrafo 2o., ${ }^{36}$ al expresar que, È compito dellaRepubblicarimuoveregliostacoli di ordine economico e sociale, che, limitando di fatto la libertà e l'eguaglianzadeicittadini, impedisconoilpienosviluppo della persona umana e l'effettivapartecipazione di tutti i lavoratoriall'organizzaz ionepolitica, economica e sociale del Paese (es responsabilidad de la República remover los obstáculos de carácter económico y social que, limitando la libertad y la igualdad de los ciudadanos, impiden el pleno desarrollo de la persona humana y la participación efectiva de todos los trabajadores en las esferas política, económica y social del país), ${ }^{37}$ en el que se establece la responsabilidad de la República italiana de ofrecer los medios propicios para que toda persona se desarrolle plenamente. Tal disposición también se conoce como cláusula Lelio Basso, ${ }^{38}$ por el diputado italiano que la redactó e incorporó a la Constitución italiana de 1947 con el objetivo de desmentir todas aquellas afirmaciones que dan por realizado lo que aún está pendiente por realizarse, como por ejemplo, la democracia, la igualdad, etcétera.

modificación de los criterios de interpretación de la legalidad hasta entonces mantenidos, apreciable mediante cualquier elemento de juicio externo.

35 Varela, Santiago, "La Constitución española en el marco del derecho constitucional comparado", en Fernández Rodríguez, Tomás R. (coord.), Lecturas sobre la Constitución española, Madrid, Universidad Nacional de Educación a Distancia, 1978, t. I, pp. 13-30, especialmente pp. 22-24.

36 Acerca del fundamento de esta normativa constitucional, véase Cerri, A., L'eguaglianzanella jurisprudencia della Corte Constituzionale, Milán, 1976; del mismo autor, Nuove note sul principio di eguaglianza, Giuridica Constitucional, 1971. También Morati, Constantino, Istituzioni di Diritto Pubblico, Padova, 1976. Paladín, Livio, "Eguaglianza", Enciclopedia di Diritto, Varesse, 1965. Del mismo autor, Il principio constituzionaled'eguaglianza, Milán, 1965.

37 La traducción es nuestra.

38 Basso, Lelio, "Giustizia e potere. La lungavia al socialismo”, Qualegiusticia, 1971, p. 654 . 
En este mismo sentido, el contenido del artículo 9o., apartado 2o., de la normativa constitucional española resulta ser prácticamente literal al artículo 3o., parágrafo 2o., de la Constitución italiana, al disponer que, Corresponde a los poderes públicos promover las condiciones para que la libertad y la igualdad del individuo sean reales y efectivas; remover los obstáculos que impidan o dificulten su plenitud y facilitar la participación de todos los ciudadanos en la vida política, económica, cultural y social. Disposición que representó la reafirmación del carácter social del Constituyente español del 78, avalando la participación activa del Estado en la superación de los obstáculos que implicasen desigualdades reales en la vida social, económica y política. No se trata pues, como pudiera parecer a primera vista, de una contradicción, por el contrario, dado que en la igualdad sustancial requiere precisamente esas desigualdades de trato, pero condicionadas a que estén dirigidas a beneficiar aquellos grupos que en la sociedad se encuentren menos favorecidos, pues sólo de esa manera se pueden justificar, cuando tengan por objetivo remover los obstáculos que impidan la igualdad efectiva y sustancial.

Es así que la Constitución española enuncia en su artículo 9o., parágrafo 2o., ${ }^{39}$ el principio de igualdad sustancial o real, y en cuyo nombre podrían justificarse la desigualdad de trato apoyadas por una justificación objetiva y razonable, esto es, bajo la denominada justificación de la diferencia $;{ }^{40}$ en

39 Sánchez Morón, Miguel, "El principio de participación en la Constitución española", Revista de Administración Pública, núm. 89, mayo-agosto de 1979, pp. 171-205, particularmente, pp. 184-185. Para un estudio completo de la historia de la Constitución española de 1978, consúltese Martínez Cuadrado, Miguel, "La Constitución de 1978 en la historia del constitucionalismo español”, en Martínez Cuadrado, Miguel (ed.), La Constitución de 1978 en la historia del constitucionalismo español, Madrid, Mezquita, 1982, pp. 1-50.

40 El propio Tribunal Constitucional faculta al legislador para contemplar y diferenciar situaciones distintas dándoles un tratamiento diverso, es decir, aplicando el criterio de generalidad y el criterio de diferenciación. De hecho es el mismo Tribunal Constitucional que contempla diversa jurisprudencia que podría considerarse opuestas entre sí, véase por ejemplo, la Sentencia TC 98/85, deL 29 de julio en la que manifiesta que el artículo 9o., apartado 2o., constitucional "contiene un mandato a los poderes públicos para que promuevan las condiciones para que la libertad e igualdad del individuo y de los grupos en que se integra sean reales y efectivos, y para que remueva los obstáculos que impidan o dificulten su plenitud, puede actuar como un principio matizador de la igualdad formal consagrada en el artículo 14 de la Constitución, permitiendo regulaciones cuya desigualdad formal se justifica en la promoción de la igualdad material, aludiendo a la prioridad por lograr la igualdad sustancial sobre la igualdad establecida en la ley; Sen- 
caso contrario, al carecer de esta justificación, el tratamiento desigualitario constituiría un tratamiento discriminatorio, y en consecuencia, sería constitucionalmente prohibido.

Como se puede observar, el contenido constitucional expresado en el numeral 9o., apartado 2o., de la Constitución española representa la cláusula de progreso e igualdad sustancial y efectiva, disposición que resulta ser aún más precisa, delimitando los instrumentos institucionales necesarios para promover la participación de los ciudadanos en la vida socioeconómica del Estado español, aludiendo a la relación existente entre la dignidad de la persona y el principio de igualdad real y efectiva, en el sentido que los derechos atribuibles sean reales y efectivos, destacando el eminente carácter ideológico de Estado social y democrático en España.$^{41}$ De esta manera prevalece como característica principal de la igualdad, el constituir un derecho atemporal y atribuible a todo ser humano, enfatizando la dimensión iusnaturalista y axiológica de la dignidad de la persona humana, como fundamento constitucional del orden público y la paz social, implícitamente consagrado en el artículo 1o., apartado 1o., de la Constitución española, de ahí que resulte necesaria la acción de los poderes públicos para garantizar la dignidad de cada persona y el pleno desarrollo de su personalidad en una sociedad económica, social y democrática. ${ }^{42}$

Es mediante este precepto constitucional mediante el cual, el Estado le otorga a la igualdad, el carácter promocional de los principios establecidos

tencia TC 49/82, del 14 de julio, en cuyo contenido se postula la doctrina constitucional respecto a los conceptos de igualdad: "el artículo 14 de la Constitución, al establecer el principio general de que los españoles son iguales ante la ley, establece un derecho subjetivo a obtener un trato igual, impone una obligación a los poderes públicos de llevar a cabo ese trato igual y, al mismo tiempo, limita el poder legislativo y los poderes de los órganos encargados de la aplicación de las normas jurídicas. La igualdad a que el artículo 14 se refiere, que es la igualdad jurídica o igualdad ante la ley, no comporta necesariamente una igualdad material o igualdad económica real y efectiva. Significa que a los supuestos de hecho iguales deben serles aplicadas unas consecuencias jurídicas que sean iguales también y que para introducir diferencias entre los supuestos de hecho tiene que existir una suficiente justificación de tal diferencia, que aparezca al mismo tiempo como fundada y razonable, de acuerdo con criterios y juicios de valor generalmente aceptados".

41 Garrorena, Ángel, op. cit., pp. 153-198, en especial, p. 58. También, Basile, S., op. cit., p. 266.

${ }^{42}$ Lucas Verdú, Pablo, Estimativa y politica constitucionales (Los valores y los principios rectores del ordenamiento constitucional español, Madrid, Universidad de Madrid, Facultad de Derecho, 1984, pp. 100-118. 
en la Constitución española, ${ }^{43}$ principio general no sólo del ordenamiento constitucional, sino de todo el ordenamiento jurídico, incorporándose en una norma programática la actuación de los órganos de los poderes públicos, en aras de alcanzar la tan anhelada igualdad sustancial, ${ }^{44}$ material, real o efectiva. ${ }^{45}$

Por tanto, podemos advertir que el precepto consagrado en el artículo 9o., apartado 2o., implica la fundamentación de la intervención de los poderes públicos en la estructura socioeconómica del Estado con miras a la realización de la igualdad efectiva y real, esto es, constituye la base constitucional que reconoce la vinculación de los órganos de los poderes públicos con el Estado social para resolver las desigualdades que de hecho operan en la sociedad, dado que la igualdad formal sólo se expresa en el plano jurídico, más no en el ámbito real caracterizado por un sinnúmero de desigualdades en las relaciones sociales. ${ }^{46}$

43 Cervati, Ángel Antonio, "El legislador de los derechos fundamentales", en López Pina, Antonio (dir.) et. al., La garantía constitucional de los derechos fundamentales. Alemania, España, Francia e Italia, Madrid, Civitas, 1991, pp. 51-75, en particular, p. 51. En este mismo sentido, Sánchez Morón, Miguel, op. cit., pp. 188-189. Freixes Sanjuan, Teresa y Remotti Carbonell, José Carlos, op. cit., p. 108.

44 Villacorta Mancebo, Luis, El principio de igualdad y Estado social. Apuntes para una relación sistemática, Cantabria, Parlamento de Cantabria-Universidad de Cantabria, 2006, pp. 67-90. Figueruelo Burrieza, Ángela, "Setenta y cinco años de sufragio femenino en España. Perspectiva constitucional”, Criterio jurídico, núm. 7, 2007, p. 156 y ss. González Martín, Nuria, "El principio de igualdad y los sistemas de protección de garantías en la Constitución española de 1978: especial referencia a la situación jurídica de la mujer", Boletín Mexicano de Derecho Comparado, Nueva Serie, año XXXIV, núm. 102, septiembre-diciembre de 2001, pp. 789-810, en especial, pp. 789-793. Moraga García, Ma. Ángeles, "La igualdad entre mujeres y hombres en la Constitución española de 1978", Feminismo/s, núm. 8, diciembre de 2006, pp. 53-69, en particular, p. 55 y ss. García Morillo, J., "La cláusula general de igualdad", Derecho constitucional. El ordenamiento constitucional. Derechos y deberes de los ciudadanos, Valencia, Tirant lo Blanch, 2000, vol. I, pp. 176 y 177.

45 Prueba de ello son, por ejemplo, la Ley13/1982, del 7 de abril, relativa a la integración social de los minusválidos; la Ley 16/1983, del 24 de octubre, mediante la cual se crea el Instituto de la Mujer, como organismo autónomo; la Ley 3/1989, del 3 de marzo, que otorga un permiso de maternidad más amplio, de dieciséis semanas, estableciendo así mismo, medidas dirigidas a favorecer la igualdad de trato de la mujer en el ámbito laboral; la Ley 39/1999, del 5 de noviembre, de conciliación de la vida familiar y laboral de las personas trabajadoras; la Ley 51/2003, del 2 de diciembre, de igualdad de oportunidades, no discriminación y accesibilidad universal de las personas con discapacidad, entre otras.

${ }^{46}$ Suay-Rincón, José, op. cit., pp. 39-44. Lucas Verdú, Pablo, op. cit., p. 70. Sánchez Morón, Miguel, op. cit., p. 176. 


\section{LA IGUALDAD DE GÉNERO EN ESPAÑA}

Resulta interesante dar a conocer el gran avance que ha experimentado la temática de igualdad de género en España, gran parte de ello derivado de la necesidad de ir adecuando su normativa con respecto al acervo comunitario europeo, especialmente en lo que a Directivas ${ }^{47}$ y jurisprudencia del Tribunal de Luxemburgo se refiere.

Si bien es cierto que la igualdad de género representa uno de los ámbitos que merecería especial desarrollo, tal apreciación rebasa los objetivos que nos hemos planteados en el presente trabajo. No obstante, consideramos de vital importancia referirnos a ella, particularmente atendiendo a la gran trascendencia y actualidad que ha supuesto, así como a la constante polémica y debate que han suscitado la implementación de medidas o instrumentos dirigidos a lograr la anhelada igualdad sustancial.

De ahí que nos enfocaremos a tres cuestiones particulares: La Ley Orgánica 3/2007, del 22 de marzo para la igualdad efectiva de Mujeres y Hombres, las sentencias del Tribunal Constitucional relativas a un tratamiento diferente en materia de violencia de género, y por último, las denominadas cuotas electorales.

\section{Ley Orgánica 3/2007, del 22 de marzo para la igualdad efectiva de Mujeres y Hombres}

Sin duda alguna, el conjunto de las normas jurídicas existentes tanto a nivel comunitario como a nivel interno, y en este caso en concreto refiriéndonos a España, la igualdad se encuentra establecida en diversos instrumentos jurídico-normativos que plasman la garantía y respeto de la igualdad entre mujeres y hombres única y exclusivamente desde un plano normativo, esto es, desde disposiciones jurídicas y formales. Hay que recordar que España es un país miembro de la Unión Europea, ${ }^{48}$ y en ésta

47 Figueroa Bello, Aída, "Las recientes directivas comunitarias adoptadas en materia de igualdad de trato entre mujeres y hombres en la Unión Europea”, en López de la Vieja de la Torre, María Teresa (coord.), Bioética y feminismo: estudios multidisciplinares de género, Salamanca, 2006, pp. 227-272.

48 Ubeda de Torres, Amaya, "La política de empleo de la UE y la igualdad entre hombres y mujeres:un desafío al futuro de Europa", Revista de Derecho Comunitario Europeo, año 7, núm. 15, 2003, pp. 699-716. Elósegui Itxaso, María, "La estrategia marco comunitaria sobre la igualdad entre hombres y mujeres (2001-2005)", Aequalitas: Revis- 
la igualdad entre mujeres y hombres constituye un principio fundamental en el ordenamiento comunitario, y el que todas las políticas de los Estados comunitarios están obligadas a contemplar en aras a conseguir la igualdad material entre mujeres y hombres. ${ }^{49}$

Ahora bien, con esta ley de Igualdad se pretende desarrollar a nivel legislativo los dos postulados básicos de la Constitución española: la igualdad formal dispuesta en el numeral 14 y la igualdad social y material consagrada en el artículo 9.2, llevando a la práctica social el cumplimiento de los postulados que representan el Estado social y democrático español (artículo 1.1 constitucional) estableciendo para ello la obligación por parte de los poderes públicos de promover todos aquellos instrumentos y condiciones para que la igualdad formal de todo individuo sea real y efectiva. ${ }^{50}$

El gobierno español — en ese entonces el Partido Socialista en el poderha desarrollado un importante número de iniciativas legales mediante las cuales se tiende a corregir las discriminaciones sociales que obstaculizan a las mujeres, tanto en su desarrollo profesional y personal en condiciones de igualdad respecto de los hombres, y teniendo como objetivo conseguir la igualdad efectiva entre mujeres y hombres en la vida social, política y económica de España. Entre ellas podemos mencionar las siguientes: Ley de

ta jurídica de igualdad de oportunidades entre mujeres y hombres, núm. 9, 2002, pp. 43 y 44 .

49 Consúltese López, Julia, "Los principios rectores de la LO 3/2007 sobre igualdad efectiva entre mujeres y hombres a la luz de las estrategias de «gender mainstreaming» y «empowerment»", Revista del Ministerio de Trabajo e Inmigración, núm. extraordinario, 2007, pp. 53-67.

50 Véase Gálvez Muñoz, Lina et. al., "La igualdad efectiva entre mujeres y hombres y el bienestar", Temas para el debate, núm. 159, febrero de 2008, pp. 58-60. Murillo de la Vega, Soledad, "La ley de igualdad efectiva entre mujeres y hombres", Estudios de derecho judicial, núm. 142, 2007, pp. 95-110. Aquino de Souza, Cristiane, "La adopción de medidas con el fin de establecer la Igualdad entre mujeres y hombres en España", Revista Jurídica Universidad Autónoma de Madrid, núm. 21, 2010, pp. 11-32. Balaguer Callejón, María Luisa, "El derecho de igualdad de género: la LO 3/2007, del 22 de marzo, para la Igualdad entre Mujeres y Hombres", en Figueruelo Burrieza, Ángela et. al. (coords.), Igualdad ¿para qué?: a propósito de la Ley Orgánica para la Igualdad efectiva de mujeres y hombres, Granada, Comares, 2007, pp. 51-70. Ayala del Pino, Cristina, "La igualdad entre mujeres y hombres a las puertas de la futura ley de igualdad en España", en González Ibáñez, Joaquín (coord.), Derechos humanos, relaciones internacionales y globalización, Colombia, Editores Ibáñez, 2006, pp. 607-618. Murcia Clavería, Ana, "La Ley Orgánica 3/2007, del 22 de marzo, para la igualdad efectiva de mujeres y hombres: un hito legislativo en la consecución de la igualdad real entre mujeres y hombres en el derecho español”, Documentación Laboral, núm. 82, 2008, pp. 11-46. 
Autonomía Personal y Atención a las Personas en Situación de Dependencia y la Ley Orgánica de Medidas de Protección Integral contra la Violencia de Género, cuyo objetivo central constituye la erradicación de la violencia ejercida contra las mujeres en todos los ámbitos de la vida social y económica de España. Cabe destacar que esta normativa contempla un conjunto de medidas y acciones en materia salarial, representación igualitaria de las mujeres en los procesos de toma de decisiones en los órganos de dirección y de responsabilidad política, ${ }^{51}$ económica y social, la difícil conciliación de la vida personal y profesional de las mujeres,${ }^{52}$ en el ámbito de la seguridad social,,$^{53}$ tolerancia cero contra la violencia de género, ${ }^{54}$ medidas de acción positiva ${ }^{55}$ aplicación de la perspectiva de género o mainstreaming,${ }^{56}$ entre otros. ${ }^{57}$ En dicha normativa española, el terreno laboral (la segregación

51 Aguado Higón, Ana María, "Mujeres y participación política entre la transición y la democracia en España”, Estudios de derecho judicial, núm. 142, 2007, pp. 165-180.

52 Tobío Soler, Constanza y Fernández Cordón, Juan Antonio, “Conciliar las responsabilidades familiares y laborales: políticas y prácticas sociales”, Documentos de trabajo (Laboratorio de alternativas), núm. 79, 2005. Garrigues Giménez, Amparo y Núñez-Cortés Contreras, Pilar, “(Des) Igualdad en las condiciones de trabajo, incluida la retribución, de los trabajadores con responsabilidades familiares: realidad actual y soluciones — parciales - planteadas en el Anteproyecto de Ley Orgánica de igualdad entre mujeres y hombres (I)", Tribuna Social: Revista de Seguridad Social y Laboral, núm. 192, 2006, pp. 23-36.

53 Barcelón Cobedo, Susana y Quintero Lima, María Gema, "El impacto de la Ley para la igualdad en el marco de la normativa de Seguridad Social", Temas Laborales: Revista Andaluza de Trabajo y Bienestar Social, núm. 91, 2007, pp. 233-262.

54 Murillo de la Vega, Soledad, "Un gesto político frente a la violencia contra las mujeres", Revista de Educación, núm. 342, 2007, pp. 167-188. También Comas de Argemir Cendra, Montserrat, "La Ley Integral contra la Violencia de Género: una ley necesaria", Revista Jurídica de Castilla y León, núm. 4, 2004, pp. 43-78. Rivas Vallejo, María Pilar, "La Ley Orgánica de igualdad entre mujeres y hombres frente a la violencia de género", Aequalitas: Revista jurídica de igualdad de oportunidades entre mujeres y hombres, núm. 20, 2007, pp. 42-55.

55 Elósegui Itxaso, María, "La Ley Orgánica de Igualdad efectiva entre mujeres y hombres. Las acciones positivas para la igualdad laboral entre mujeres y hombres", Cuadernos de derecho judicial, núm. 5, 2007, pp. 13-52. Bengoechea Gil, María Ángeles, "Acciones positivas y discriminaciones inversas: dos instrumentos para hacer efectiva la igualdad entre hombres y mujeres”, en Cruz Sánchez de Lara Sorzano (coord.), Mujeres: igualdad y libertad: un homenaje a Enriqueta Chicano, España, Civitas, 2007, pp. 63-94.

56 Véase Lombardo, Emanuela, "El Mainstreaming: la aplicación de la transversalidad en la Unión Europea", Aequalitas, Revista Jurídica de Igualdad de oportunidades entre mujeres y hombres, núm. 13, 2003, pp. 5-11.

57 Consúltese Caballero Gea, José-Alfredo, "Procedimientos contencioso-administrativos: síntesis y ordenación de la doctrina de los tribunales y fiscalía general del esta- 
ocupacional ${ }^{58}$ y la desigualdad retributiva entre mujeres y hombres) constituye uno de sus ejes centrales de acción dirigidas a obtener la equiparación laboral ${ }^{59}$ y socioeconómica de mujeres y hombres, con el objetivo de conseguir la igualdad real y efectiva entre ambos, y de esta manera hacerle frente a las discriminaciones por razón de sexo de carácter estructural en el sistema social español, al prevalecer patrones y estereotipos socioculturales, situando a las mujeres en clara desventaja social y económica con respecto a los varones.

\section{Sentencias del Tribunal Constitucional de diferente trato entre mujeres y hombres en materia de violencia de género}

Como punto de partida debemos aludir que la violencia ejercida contra las mujeres se ha caracterizado como una forma de discriminación por razón de sexo, atentando y lesionando sus derechos humanos y de inicio, el derecho a su dignidad personal, actos violentos que se suscitan, generalmente en el entorno familiar, o bien, en las relaciones de convivencia, en este caso, en la relación de pareja, independientemente expresada en vínculo jurídico o de hecho, ${ }^{60} \mathrm{o}$ inclusive en ausencia del mismo, en los casos de separación

do: actualizado con las formas introducidas por la Ley Orgánica 3-2007, 22 de marzo", Igualdad efectiva de mujeres y hombres, Madrid, Dykinson, 2007. Pérez Campos, Ana Isabel, "Igualdad y no discriminación en la negociación colectiva", Anuario Jurídico y Económico Escurialense, núm. 43, 2010, pp. 143-174. Comas de Argemir Cendra, Monserrat, "El principio de igualdad de oportunidades entre hombres y mujeres en la carrera judicial", Estudios de derecho judicial, núm.142, 2007, pp. 23-94. Papí Gálvez, Natalia y Orbea Mira, Jesús, "La eficacia publicitaria de las campañas sobre la igualdad de género: análisis de la codificación y del plan de medios", Zer: Revista de Estudios de Comunicación = Komunikazio ikasketen aldizkaria, núm. 30, 2011, pp. 247-266.

${ }^{58}$ Lesmes Zabalegui, Santiago, "Contratación pública y discriminación positiva. Cláusulas sociales para promover la igualdad de oportunidades entre mujeres y hombres en el mercado laboral", Lan Harremanak: Revista de Relaciones Laborales, núm. 13, 2005, pp. 53-86.

${ }^{59}$ Chacartegui Jávega, Consuelo, "El largo recorrido hacia igualdad de oportunidades entre hombres y mujeres en el ámbito laboral: un avance significativo con las medidas previstas en la Ley Orgánica de Igualdad”, Revista Jurídica de Catalunya, vol. 106, núm. 1, 2007, pp. 75-104.

${ }^{60}$ Véase Lorente Acosta, Miguel, "Elementos y consideraciones para una solución integral de la violencia de género", en Pérez Fernández, Miguel et. al. (coords.), Sociedad, violencia y mujer. Retos para afrontar la desigualdad, Salamanca, Amarú, 2005, pp. 99-128, en particular pp. 101-107, quien alude a que las normas sociales han justificado 
o bien, de divorcio, conductas que resultan hechos constitutivos de delitos en la esfera jurídica, y en la que de igual modo se lucha por su erradicación.

Hemos de señalar que España ha sido uno de los países comunitarios en los que por desgracia, la violencia de género ha experimentado cifras alarmantes y que incluso en la gran mayoría de los casos se ha causado la muerte de la víctima. Y ha sido precisamente atendiendo a ello, que en 2004 se aprueba una normativa de enorme y gran trascendencia, ${ }^{61}$ nos referimos a la Ley Orgánica 1/2004, del 28 de diciembre, de Medidas de Protección Integral contra la Violencia de Género, publicada en el Boletín Oficial del Estado el 29 de diciembre de ese mismo año, lo que ha supuesto un paso de gigante desde el punto de vista sociojurídico en la lucha contra la violencia de género. ${ }^{62}$

Es de destacarse que esta legislación ha sido reflejo de la visibilidad de los actos de violencia de género, dado que aún cuando se ha manifestado a través de actos violentos contra las mujeres en el seno familiar, esto es, en el plano estrictamente privado, ha sido de tal magnitud que se ha tornado una cuestión de carácter público. Su estructura contempla un título preliminar, cinco títulos, veinte disposiciones adicionales, dos disposiciones transitorias, una disposición derogatoria y siete disposiciones finales. Incluye diversas medidas enfocándose a distintos ámbitos: preventivos, educativos, sociales, asistenciales, de atención a la victimas,

los actos violentos ejercidos por el hombre sobre la mujer, atribuyéndole el carácter de causas o factores a trastornos del hombre, o bien de la mujer, aludiendo al mismo tiempo a un tipo de despreocupación por parte de la sociedad al restarle la gran trascendencia que esta problemática social implica, prevaleciendo factores como por ejemplo, la hipermasculinidad, duración prolongada en la relación sentimental, el predominio de los modelos sexuales, entre otros. En este mismo sentido consúltese, Maqueda Abreu, María Luisa, "La violencia de género: entre el concepto jurídico y la realidad social", Revista Electrónica de Ciencia Penal y Criminología, febrero de 2006, pp. 1-13. Guillén Soria, José Miguel, "Introducción. Violencia doméstica ejercida sobre la mujer. Elementos socioculturales y económicos que determinan su existencia”, en Carrasco Gómez, Juan José (coord.), Estudios sobre la violencia familiar y agresiones sexuales, Madrid, Ministerio de Justicia-Ministerio de Trabajo y Asuntos Sociales-Instituto de la Mujer, 2000, t. I, pp. 99-126, en particular, p. 106.

61 Véase Montalbán Huertas, Inmaculada, "Ley orgánica 1/2004, del 28 de diciembre, de Medidas de Protección Integral contra la Violencia de Género. un instrumento normativo novedoso", Cuadernos de Derecho Judicial, núm. 22, 2005, pp. 25-98.

62 Cfr. Alastuey Dobón, María del Carmen, "Desarrollo parlamentario de la ley integral contra la violencia de género. Consideraciones críticas”, en Rueda Martín, María Ángeles y Boldova Pasamar, Miguel Ángel (coords.), La reforma penal en torno a la violencia doméstica y de género, Barcelona, Atelier, 2006, pp. 57-68. 
como toda la normativa civil que relativa al ámbito familiar, así como también el aspecto punitivo atendiendo las numerosas manifestaciones de violencia contra las mujeres. En este sentido destacamos lo expresado en su artículo 1o.:

La presente Ley tiene por objeto actuar contra la violencia que, como manifestación de la discriminación, la situación de desigualdad y las relaciones de poder de los hombres sobre las mujeres, se ejerce sobre éstas por parte de quienes sean o hayan sido sus cónyuges o de quienes estén o hayan estado ligados a ellas por relaciones similares de afectividad, aun sin convivencia.

Ahora bien, en el plano judicial la normativa española crea nuevos juzgados de violencia contra la mujer, así como plazas de fiscales especializados en violencia de género. Y por lo que se refiere a la esfera jurisdiccional, ésta ha tenido enorme protagonismo, dado que a través de las sentencias pronunciadas por el Tribunal Constitucional español se han dado a conocer numerosos criterios jurisprudenciales que a primera vista se podrían considerar discriminatorios, ${ }^{63}$ puesto que en gran parte de sus resoluciones se ha declarado un tratamiento jurídico diferente de los hombres respecto de las mujeres, especialmente nos referimos al elemento punitivo.$^{64}$ En este mismo sentido podemos citar ejemplos de algunas sentencias que versan sobre el análisis de las cuestiones de constitucionalidad en la aplicación del artículo

${ }^{63}$ Véase por ejemplo las posturas de Bolea Bardon, Carolina, "En los límites del Derecho penal frente a la violencia doméstica y de género", Revista Electrónica de Ciencia penal y Criminología, núm. 9, 2007, pp. 2-24. En una postura inversa, véase Acale Sánchez, María, La discriminación hacia la mujer por razón de sexo en el Código Penal, Madrid, Reus, 2006; de la misma autora, "Análisis del Código penal en materia de violencia de género contra las mujeres desde una perspectiva transversal", Revista Electrónica del Departamento de Derecho de la Universidad de la Rioja, núm. 7, 2009, pp. 25-35. Mirat Hernández, Carmen Pilar y Armendáriz León, Carmen, Violencia de género versus violencia doméstica, Valencia, Difusión Jurídica y Temas de Actualidad, 2007, en especial pp. 117 y ss.

${ }^{64} \mathrm{Y}$ de hecho desde el ámbito de la técnica jurídica insertada en el contenido de la Ley, en la que el legislador hace referencia al sexo del agresor (varón) y de la agredida o víctima (mujer), particularidades de la que se han derivado diversas cuestiones de inconstitucionalidad presentadas al Tribunal Constitucional español, aspectos que atendiendo a la interpretación de la normativa, indubitablemente identificaríamos al varón como autor y a la mujer como la víctima. Véase Sanmartín, Olga R., "El 80\% de las sentencias de violencia de género condena al agresor", El Mundo, 10 de febrero de 2010, en $h t t p: / / w w w$. elmundo.es/elmundo/2010/02/09/espana/1265719274.html. 
153.1 del Código Penal, ${ }^{65}$ reformado a raíz de la entrada en vigor de la ley en comento, que ha sido de todo menos polémica y discutida, incluso antes de resultar normativa vigente. ${ }^{66}$ Es de suma importancia señalar que todas las sentencias que se han declarado referidas a la materia de violencia de género, han venido a corroborar la constitucionalidad de la Ley Orgánica 1/2004 en lo que se refiere al tipo penal de mal trato singular en el ámbito familiar, expresado en el artículo 153.1 del Código Penal. Pues bien, la primera de estas sentencias es la 59/2008, del 14 de mayo — declarando el órgano jurisdiccional que dicho numeral es conforme a los preceptos constitucionales y por ende, expresando su carácter vinculante a todos los jueces y Tribunales de España—, ${ }^{67}$ seguida de otras más: 76/2008, del 3 de julio; 81, 82 y 83/2008, del 17 de julio; 95, 96, ${ }^{68}$ 97, 98, 99 y 100/2008, del 24 de julio, resoluciones que en concreto, contienen los argumentos expresados en la primera. Y por lo que se refiere a la sentencia 45/2009, de 19 de febrero, en ella se estudia

65 Artículo que en su momento ha sido modificado por la Ley Orgánica 11/2003, del 29 de septiembre y por Ley Orgánica 1/2004, del 28 de diciembre), y que a la letra señala lo siguiente: El que por cualquier medio o procedimiento causare a otro menoscabo psíquico o una lesión no definidos como delito en este Código, o golpeare o maltratare de obra a otro sin causarle lesión, cuando la ofendida sea o haya sido esposa, o mujer que esté o haya estado ligada a él por una análoga relación de afectividad aun sin convivencia, o persona especialmente vulnerable que conviva con el autor, será castigado con la pena de prisión de seis meses a un año o de trabajos en beneficios de la comunidad de treinta y uno a ochenta días y, en todo caso, privación del derecho a la tenencia y porte de armas de un año y un día a tres años, así como, cuando el juez o tribunal lo estime adecuado al interés del menor o incapaz, inhabilitación para el ejercicio de la patria potestad, tutela, curatela, guarda o acogimiento hasta cinco años.

66 Véase por ejemplo, Asúa Batarrita, Adela, "La ley de medidas de protección integral contra la violencia de género", Cuadernos Penales José Moría Lidón, núm. 2, Bilbao, Universidad de Deusto, 2005, p. 10 y ss. También Villacampe Astlarte, Carmen, "El maltratado singular cualificado por razón de género: debate acerca de su constitucionalidad", Revista Electrónica de Ciencia Penal y Criminología, núm. 9-12, 2007. La polémica que ha supuesto esta ley ha correspondido a integrar una normativa penal sexuada, integrando medidas de protección dirigidas de manera exclusiva a las mujeres en su calidad irremediable de víctimas o agredidas por actos violentos por el varón, aspectos que no tardaron en provocar severas críticas, aún en la doctrina española.

67 Cfr. Rubio de la Torre, José Luis, Ley de violencia de género. Ajuste de constitucionalidad en materia penal, Valencia, Tirant lo Blanch, 2007, pp. 81 y ss.

68 Un aspecto curioso es el caso de esta sentencia, 96/2008, y que cuenta con la primicia en el análisis específico de los malos tratos mutuos. 
el delito de amenazas expresado en el artículo $171.4^{69}$ de la normativa penal española, afirmándose que no resulta inconstitucional, ${ }^{70}$ reiterando los argumentos vertidos en la sentencia inicial del Tribunal Constitucional.

En este sentido, el órgano jurisdiccional reitera sus argumentos en las sentencias en materia de violencia de género, es decir, que podríamos observar un Tribunal Constitucional un tanto tímido y ajeno a desarrollar criterios que en gran medida brindaría luces a las numerosas sombras y críticas que ha supuesto la aprobación de la Ley $1 / 2004$. Si bien es cierto que se trata de ofrecer respuestas jurídicas desde un punto de vista punitivo, a una problemática de violencia de género de tal gravedad que aqueja a la sociedad española, llevando a cabo distinciones en el trato del agresor con respecto a la víctima, habría una justificación razonable, y que en todo caso corresponde paliar estos actos lesivos de la dignidad, integridad y bienestar de las mujeres, fortaleciendo sus derechos violentados. Quizá se ha atendido mucho más a la finalidad que a sus consecuencias.

\section{Las cuotas electorales}

Históricamente la mujer se ha encontrado relegada al mundo privado (familiar, casa, crianza de los hijos), o bien, a las denominadas tres Kas (Kirche, Kinder, Küchen ${ }^{71}$ y por ende, ausente en el plano público y en el

69 A la letra dice: "El que de modo leve amenace a quien sea o haya sido su esposa, o mujer que esté o haya estado ligada a él por una análoga relación de afectividad aun sin convivencia, será castigado con la pena de prisión de seis meses a un año o de trabajos en beneficio de la comunidad de treinta y uno a ochenta días y, en todo caso, privación del derecho a la tenencia y porte de armas de un año y un día a tres años, así como, cuando el Juez o Tribunal lo estime adecuado al interés del menor o incapaz, inhabilitación especial para el ejercicio de la patria potestad, tutela, curatela, guarda o acogimiento hasta cinco años.

Igual pena se impondrá al que de modo leve amenace a una persona especialmente vulnerable que conviva con el autor".

${ }^{70}$ Los motivos de inconstitucionalidad que se alegaban correspondían por ejemplo, a la supuesta vulneración del principio de igualdad ante la ley, de culpabilidad, dignidad de la persona y presunción de inocencia, entre otros.

71 Así, por ejemplo, en el caso de Alemania, con el nuevo programa de Bund Deustcher Frauenvereine establecía el ámbito femenino y los deberes de las mujeres al servicio de la comunidad nacional, en absoluta armonía con tal ideología. Véase Bock, Gisela, La mujer en la historia de Europa, trad. de Lozoya de Teófilo, Barcelona, Crítica, 2001, p. 57. Para un estudio sistematiza o sobre la historia de la mujer en Europa, véase Bridenthal, Renate y Koonz, Claudia, "Mas allá de Kinder, Küche, Kirche: las mujeres 
caso español no ha sido la excepción. Y recientemente la visión estadual gubernamental ha centrado su atención a paliar la infrarrepresentación de las mujeres en los círculos o espacios de poder, ${ }^{72}$ implementando medidas tales como las cuotas electorales que no son otra cosa que medidas legislativas y administrativas orientadas a fomentar la igualdad entre mujeres y hombres en la denominada arena pública.$^{73}$ Aunado a lo anterior, siendo escasa la participación y representación política de las mujeres en los cargos de poder, las que los ocupan se encuentran en áreas por ejemplo, de educación cultura, turismo, medio ambiente, juventud, deporte, esto es, ámbitos en los cuales tradicionalmente se han considerado adecuadas o pertinentes para la mujer, carteras de menor importancia desde el punto de vista político con presencia femenina. Resulta interesante citar por ejemplo, la composición del gabinete del ex presidente José Luis Rodríguez Zapatero, en el cual nueve de sus Ministerios se encontraban representados por una mujer. ${ }^{74}$

de Weimar en la política y en el trabajo", trad. de Eugenio y Marta Portela, en Amelang, James S. y Nash, Mary (eds.), Historia y género: las mujeres en la Europa moderna y contemporánea, Valencia, Alfons el Magnánim, Institució Valenciana d'Estudis I Investigació, 1990, p. 349.

72 Alfonso Sánchez, José Manuel y Diestro Fernández, Alfonso, La nueva gobernanza. La participación de la mujer en la política de la Unión Europea, Salamanca, Oficina de Promoción Económica y Empleo del Excelentísimo Ayuntamiento de Salamanca, 2005, p. 10.

73 Ruiz Miguel, Jesús Alfonso, "Ciudadanía y derechos de las mujeres: un largo camino abierto", en González Ruiz, Pilar et. al., El movimiento feminista en España en los años setenta, Valencia, Cátedra Universitat de València, 2009, pp. 131-170, en particular, pp. 22 y ss., quien alude a la representación política femenina como un claro ejemplo de ambiente democrático. Krennerich, Michael, "Mujeres al parlamento. Sistemas electorales y cuotas de género en la mirilla”, en Reynoso Núñez, José y Sánchez de la barquera y Arroyo, Herminio (coords.), La democracia en su contexto. Estudios en homenaje a Dieter Nohlen en su septuagésimo aniversario, México, UNAM, Instituto de Investigaciones Jurídicas, 2009.

74 Véase Algañaraz, Juan Carlos, "Nuevo gabinete de Zapatero: por primera vez hay mayoría de mujeres”, El Mundo, 13 de abril de 2008. También García-Nicolás, Cristina, "Igualdad de oportunidades en la Unión Europea y en España", en Flecha Andrés, JoséRomán y García-Nicolás, Cristina (coords.), Mujer e igualdad de oportunidades, Salamanca, Universidad Pontificia de Salamanca, Instituto de Estudios Europeos y Derechos Humanos, 2004, p. 125. Por ejemplo, Elena Salgado (vicepresidenta para Asuntos Económicos y ministra de Economía y Hacienda), Trinidad Jiménez (ministra de Asuntos Exteriores y de Cooperación), Carme Chacón (ministra de Defensa), Leire Pajín (ministra de Sanidad, Política Social e Igualdad), Rosa Aguilar (ministra de Medio Ambiente y Medio Rural y Marino), Ángeles González-Sinde (ministra de Cultura), Cristina Garmendia (ministra de Ciencia e Innovación). 
Pues bien, los sistemas de cuotas electorales ${ }^{75}$ no son otra cosa que la reserva de plazas en las listas electorales de los partidos políticos nacionales para ser ocupadas por representación femenina, este sistema ha significado un considerable logro en la participación de las mujeres en el mundo de la política, ${ }^{76}$ aún cuando haya todavía cierta reticencia en considerar a este mecanismo como un instrumento destinado a lograr una igualdad real entre mujeres y hombres en el entorno público. ${ }^{77}$

75 Entre la abundante bibliografía se puede consultar Verge Mestre, Tània, "Cuotas voluntarias y legales en España. La paridad a examen", Revista Española de Investigaciones Sociológicas, núm. 123, 2008, pp. 123-150. De la misa autora, "Mujer y partidos políticos en España: las estrategias de los partidos y su impacto institucional, 1978-2004", Revista Española de Investigaciones Sociológicas, núm. 115, 2006, pp. 165-96, así como "Mujer y partido político en España. Las estrategias de los partidos y su impacto institucional”, Revista Española de Investigaciones Sociológicas, núm. 115, pp. 165-196. También Jenson, Jane y Valiente, Celia, "El movimiento a favor de la democracia paritaria en Francia y España", Revista Española de Ciencia Política, núm. 5, 2001, pp. 79-110. Martínez Pérez, Álvaro y Calvo Borobia, Kerman, Un análisis del efecto de la Ley de igualdad en la representación electoral, parlamentaria y en el comportamiento electoral de las mujeres en las elecciones generales de 2008, Madrid, Fundación Alternativas, 2009. Serra, Cristóbal, Rosario y Oñate, Pablo, "La presencia de la mujer en los parlamentos en España: cantidad y calidad de la paridad", VII Congreso Mundial de la Asociación Internacional de Derecho Constitucional 6-10 de diciembre de 2010, Madrid, 2010. Figueruelo Burrieza, Ángela, "Representación política y democracia paritaria (A propósito de la sentencia del TC 12/2008, del 29 de enero)", Revista Europea de Derechos Fundamentales, núm. 12, 2008, pp. 211-233. Oñate Rubalcaba, Pablo y Delgado, Irene, "Partidos, grupos parlamentarios y diputados en las asambleas autonómicas", en Oñate, Pablo (ed.), Organización y funcionamiento de los Parlamentos Autonómicos, Valencia, Tirant lo Blanch, 2006.

76 Sánchez Díez, Ingrid Estibaliz, "La participación de la mujer en política”, en Martínez Gallego, Eva María y Reguero Celada, Justo (coords.), Mujer y empleo. Una estrategia para la igualdad, Granada, Comares, Colección Trabajo y Seguridad Social, núm. 18, Granada, 2004. pp. 73-86. En este mismo sentido, véase, Mateos, Araceli, y Ruíz Rodríguez, Leticia M., "Mujer y política en Europa: niveles de participación y representación política femenina en la Unión Europea”, en Figueruelo Burrieza, Ángela y López de la Vieja, Teresa et. al., (eds.), Las mujeres en la Constitución europea. Estudios multidisciplinares de género, colección Aquilafuente, núm. 87, Salamanca, Ediciones Universidad de Salamanca-Centro de Estudios de la Mujer, 2005, pp. 91-115.

77 Véase por ejemplo, Tocino, Isabel, Por una democracia paritaria, Madrid, Instituto de la Mujer, 2004, pp. 19-23, quien expresa a todas luces su negativa a considerar este sistema de cuotas como una opción viable para conseguir la igualdad de oportunidades, apreciándolo como un mecanismo que en sí mismo, implica discriminación para la mujer, aludiendo más bien a la existencia de listas abiertas integradas por mujeres para acceder a ocupar cargos de decisión política. En esta misma línea, Rey Martínez, Fernando, "Cuotas electorales reservadas a mujeres y Constitución", Aequalitas, Revista 
De ahí que consideremos que el sistema de cuotas básicamente se refiere a la condicionante que las mujeres integren un determinado número o porcentaje, ya sea en listas electorales, ${ }^{78}$ en un comité o asamblea parlamentaria con el objetivo de reservarles puestos en las instituciones y en los ámbitos de decisión, todo ello con la idea que no queden fuera de la vida política, en donde la cuestión relevante se encuentra ya no en la mujer individualmente considerada, sino en quienes se encargan de la elección de los candidatos.

Se debe apuntar que este sistema de cuotas ha permitido que de manera paulatina, en España se conciba un aumento en la presencia femenina en los órganos de poder de la mayoría de los países democráticos, estando representada en porcentajes cercanos a un $50 \%$, sin embargo aún queda una

Jurídica de Igualdad de Oportunidades entre Mujeres y Hombres, núm.1, mayo de 1999, quien a nuestro modo de ver las cosas, considera el sistema de cuotas desde otro punto de vista, desde la perspectiva del derecho constitucional español, estimando tal sistema como un instrumento violatorio de diferentes derechos expresamente considerados como fundamentales: libertad de asociación (artículo $22 \mathrm{CE}$ ), libertad de ideología (artículo 16.1 CE), principio de no discriminación por razón de sexo (artículo $14 \mathrm{CE}$ ), entre otros, aseverando que este tipo de medidas tienden a conseguir una igualdad en el punto de partida, esto es, una igualdad de oportunidades, no así una igualdad de resultados, dado que seguirán prevaleciendo las diferencias entre la posición de las mujeres y hombres en lo que a representación política se refiere.

78 Hay que señalar que en el caso de España, han sido precisamente los partidos políticos quienes han promovido esta herramienta igualitaria, en donde se han implementado una serie de medidas para el fomento de la participación femenina dentro de estas organizaciones políticas, sobre el particular consúltese, Álvarez Durante, María Luisa, Coloquio celebrado en el Senado el 11 de marzo de 1994, Las mujeres y el poder político, Serie Debate, núm. 16, Madrid, Ministerio de Asuntos Sociales, Instituto de la Mujer, 2004, pp. 64-68, especialmente, pp. 65 y 66, quien sostiene que España es el cuarto Estado con mayor representación parlamentaria femenina de la Unión Europea, haciendo referencia a los datos parlamentarios correspondientes en los panoramas: estatal, locales y autonómicos de España. También consúltese Sevilla, Julia, "Género y Estado", en Campillo Iborra, Neus (coord.), Género, ciudadanía y sujeto político. En torno a las políticas de igualdad, Valencia, Institut Universitari d'Estudis de la Dona-Universitat de València, 2010, pp. 117-136, en particular, pp. 129-136, quien pone de manifiesto la importancia de los partidos políticos como organizaciones en las que se lleva a cabo la aplicación de cuotas electorales para garantizar un avance significativo en la participación de las mujeres en el proceso de toma de decisiones, y especialmente en las decisiones políticas. Threfall, Monica, "Explaning Gender Parity Representation in Spain: The Internal Dynamics of Parties", West European Politics, Issue 5, pp. 1068-1095. Serra Cristóbal, Rosario, "La presencia de las mujeres en los parlamentos autonómicos. La efectividad de las medidas adoptadas por los partidos políticos y por el legislador", Revista de Estudios Políticos, núm. 141, 2008, pp. 161-195. 
gran brecha por recorrer en la democracia paritaria, en donde las mujeres puedan representar sus propios intereses e inquietudes. ${ }^{79}$

\section{CONCLUSIONES}

Así pues, y en vista de todo lo expuesto, se observa que existen dos tipos de igualdad: la igualdad formal, consagrada como cláusula general en la primera parte del artículo 14, y que se traduce en que todos los españoles son iguales en la ley, aún cuando, la realidad dista mucho de lo que es establecido por la norma jurídica, esto es, ya no basta con una igualdad ante la ley, sino que este precepto se lleve a la práctica en un Estado social y democrático de derecho, para lo cual se requiere un conjunto de medidas aplicadas con miras a eliminar los obstáculos que impiden la igualdad real y efectiva, disposición expresa en el artículo 9o., apartado 2o., de la Constitución española.

Por tanto, podríamos considerar que la relación entre los dos contenidos normativos de la Constitución española estriba en el hecho de que el objetivo a alcanzar lo constituye la igualdad material y efectiva, postulada en el artículo 9o., apartado 2o., razón que exigiría la desigualdad formal ${ }^{80} \mathrm{En}$ otras palabras, que la aplicación de aquellas medidas — que en principio podrían suponer una desigualdad — se justificarían, al obtener una igualdad

79 Ortega, Carmen y Trujillo José M., "Cuotas legales de género y sistemas electorales: las elecciones a Cortes Generales de 2008", Ponencia presentada al X Congreso de la Asociación Española de Ciencia Política y de la Administración, Murcia, 7-9 de septiembre de 2011. Aquino de Souza, Cristiane, "Las cuotas electorales y los derechos fundamentales", Universitas. Revista de Filosofía, Derecho y Política, núm. 13, enero de 2011, pp. 37-66. En especial, consúltese Rey Martínez, Fernando, Discriminación por razón de género y sistema electoral en Europa y España, México, Tribunal Electoral del Poder Judicial de la Federación, 2009.

80 Es precisamente esta cuestión que enlaza los dos artículos, donde resulta imprescindible la intervención de los poderes públicos para que la igualdad formal se traduzca en una igualdad real y efectiva de los derechos y prerrogativas sociales de los ciudadanos en un Estado social de Derecho. Así lo expresó el Tribunal Constitucional en Sentencia TC 98/85 del 29 de julio, donde manifestaba que la desigualdad formal se justifica en la promoción de la igualdad material, pues lo que resulta verdaderamente prioritario es proteger a los grupos sociales menos favorecidos que tradicionalmente han sido discriminados. Consúltese, Pérez Luño, Antonio Enrique, "Dimensiones de la igualdad material", Anuario de Derechos Humanos, núm. 3, 1984-1985, pp. 253- 285. Del mismo autor "El concepto de igualdad como fundamento de los derechos económicos, sociales y culturales", Anuario de Derechos Humanos, núm. 1, 1981, pp. 254-275. 
de resultados, y por consiguiente, que de acuerdo al precepto constitucional en cuestión, resulta prioridad alcanzar la igualdad sustancial y con miras a ello, se justificarían las diferencias de trato; son el caso de las acciones positivas o afirmativas, ${ }^{81}$ mediante las cuales se otorga un tratamiento preferente a aquellos sectores sociales que tradicionalmente han sufrido discriminación, o bien desigualdad de oportunidades.

En este sentido, resulta limitativo considerar a la disposición constitucional expresada en el artículo 9o., apartado 2o., un complemento material de lo que establece el precepto 14 constitucional, toda vez que va más allá de una mera adición, puesto que implica el fundamento de todos los derechos fundamentales establecidos en la propia Constitución, y en general, de todo el ordenamiento jurídico consagrado de la Constitución española. ${ }^{82}$ Por consiguiente, podemos entender que la igualdad sustancial tiene un carácter eminentemente promocional, estrechamente relacionado con otros artículos de contenido social, tal es el caso del artículo 35, apartado 1o., disposición constitucional que expresa el derecho de todos los españoles a la promoción laboral y a una remuneración suficiente para la satisfacción de sus necesidades; o bien, el numeral 41 que establece la obligación del Estado español a garantizar un conjunto de prestaciones sociales en un sistema público de seguridad social.

Esta segunda dimensión del principio de igualdad incorporado en la Constitución española alude al mandato orientado al poder público para que lleven a cabo, dentro de su ámbito competencial, todas aquellas medidas para lograr la igualdad sustancial. A este respecto, diremos que la igualdad material es el fundamento de los principios rectores de la política económica y social consagrados en el capítulo III de la Constitución española. ${ }^{83}$

Esta igualdad sustancial es una clara expresión de un Estado social y democrático de derecho, en donde los poderes públicos tienen legitimidad para promover aquellos medios dirigidos a conseguir una igualdad real y efectiva, y a su vez, remover los obstáculos que impidan su plena realización. ${ }^{84}$

81 Véase, Gímenez Gluck, Diego, Una manifestación polémica del principio de igualdad. Acciones positivas moderadas y medidas de discriminación inversa, Valencia, Tirant lo Blanch, 1999. También Ruíz Miguel, Alfonso, "Discriminación inversa e igualdad", en Valcárcel, Amelia (comp.), El concepto de igualdad, Madrid, Pablo Iglesias, 1994, pp. 77-93.

82 Garrorena, Ángel, op. cit., pp. 57-66.

${ }^{83}$ Lucas Verdú, Pablo, op. cit., pp. 190-209.

84 Arozamena Sierra, Jerónimo, op. cit., p. 423. 
Es de destacar que la igualdad sustancial implica dos cuestiones: la igualdad de oportunidades y la igualdad de resultados ${ }^{85}$ referida fundamentalmente a la satisfacción de las necesidades de todos los ciudadanos, objetivo común que caracteriza, dentro del constitucionalismo contemporáneo, al Estado social de derecho en un sistema político democrático.

De acuerdo a lo que hemos expresado en las líneas anteriores, podemos señalar que el principio de igualdad impone que los tratamientos desiguales no sean arbitrarios, injustificados e irrazonables, esto es, que carezcan de justificación objetiva, pues si así fuera estaríamos en presencia de una conducta o trato discriminatorio con independencia del criterio de diferenciación aplicado. ${ }^{86}$ En este sentido, el principio de no discriminación no es absoluto,${ }^{87}$ sino que acepta la discriminación jurídica formal para alcanzar la anhelada igualdad sustancial, tal es el caso de la discriminación inversa o las llamadas acciones positivas, medidas tendientes a favorecer a grupos

85 Véase, Alarcón Cabrera, Carlos, "Reflexiones sobre la igualdad material", Anuario de Filosofía del Derecho, Madrid, nueva época, t. IV, 1987, pp. 31-43, en particular pp. 33 y 34, quien divide la igualdad material en dos vertientes: la igualdad de punto de partida, igualdad de oportunidades, y la igualdad de llegada o igualdad de resultados, considerando a la primera como el tener las mismas oportunidades sin obstáculos que se traduzcan en tratos discriminatorios que impidan acceder a la obtención de medios y bienes materiales e inmateriales, y en general, al desarrollo humano en libertad e igualdad; y respecto a la segunda, advierte que son la consecuencia de aquellas medidas implementadas por los poderes públicos para el logro de la satisfacción de necesidades básicas del ser humano. Cfr. Strauss, David A., "The Illusory Distinction between Equality of Opportunity and Equality of Result", William and Mary Law Review, vol. 34, núm. 171, 1992 y 1993, pp. 171-188, en particular pp. 177-185.

${ }^{86}$ Por su parte, en el artículo 14 del Convenio Europeo de Derechos Humanos expresa que una discriminación corresponde a toda diferencia de trato en el ejercicio de los derechos y libertades reconocidos, carente de justificación objetiva. Conviene añadir que en cuanto a la igualdad, el Convenio dispone la cláusula general de igualdad en términos de garantizar la no discriminación pero referido al goce y disfrute de los derechos y libertades reconocidos en él, es por ello que el Tribunal de Estrasburgo ha emitido su jurisprudencia considerando a la igualdad no como un derecho autónomo e independiente, sino siempre referido a la defensa de los otros derechos consagrados en el Convenio. En este sentido consúltese, García de Enterría, E. et al., El sistema europeo de protección de los derechos humanos, Madrid, Civitas, 1979. En la doctrina existe cierta discrepancia en cuanto a la consideración del principio de igualdad como derecho fundamental autónomo y como principio constitucional, véase al respecto Rodríguez Piñero, Miguel y Fernández, María Fernanda, Igualdad y discriminación, Madrid, Tecnos, 1986, p. 255.

87 Como señala Laporta, Francisco J., op. cit., p. 13, el principio de igualdad determina en qué situaciones se justifica aplicar diferencias en las consecuencias normativas y en cuáles no, es por ello que podemos considerar al principio de igualdad como relativo. 
menos favorecidos socialmente e incluso diríamos, considerados bajo ciertos estereotipos sociales de manera negativa, representándoles una situación discriminatoria. ${ }^{88}$

Es importante destacar que la discriminación requiere una justificación mucho más especial, a diferencia del tratamiento desigual, en el que sólo bastaría una justificación objetiva y razonable. En el supuesto de la discriminación, el Tribunal Constitucional español ha emitido el denominado test del efecto o del impacto compensador, el cual determinará si las medidas discriminatorias aplicadas tienen como resultado paliar los efectos de la desigualdad real o social, ${ }^{89} \mathrm{y}$ en donde no todo acto discriminatorio resulta injusto o arbitrario.

Pues bien, como podemos deducir, el acto discriminatorio atiende a cuestiones fundamentalmente sociales, en las que determinados grupos de individuos son discriminados en la sociedad. Y es precisamente este segundo plano del principio de igualdad que determina el cambio del Estado liberal ${ }^{90}$ al Estado social de derecho, donde se pretende garantizar, ya no sólo la igualdad formal, sino también la igualdad real, la igualdad en la sociedad española.

Y a raíz precisamente de lograr la igualdad, ya no sólo de facto, de igualdad de trato, o bien, la igualdad de punto de partida, sino una efectiva igualdad de oportunidades entre mujeres y hombres en la dinámica social y política de España resulta innegable la necesidad de cambio de mentalidades, de actitudes respecto a la presencia de la mujer en los diferentes entornos de la sociedad, especialmente en el ámbito laboral, así como en los centros de decisión y responsabilidad política, configurándose de esta manera la tan anhelada igualdad de resultados, igualdad real y sustancial en España. Y un claro reflejo de ello han sido las diversas normativas apro-

88 Rey Martínez, Fernando, op. cit., p. 30.

89 Consúltese Sentencia TC 128/87, del 16 de julio, en la que se alude a la distinción entre las medidas que tradicionalmente protegen a la mujer, y aquéllas cuyo objetivo es eliminar la discriminación que sufren determinados grupos sociales, entre ellos la mujer considerada como colectivo y que por razón de sexo ha sido discriminada en el ámbito laboral declarando que "las medidas protectoras de aquellas categorías de trabajadoras que estén sometidas a condiciones especialmente desventajosas para su acceso al trabajo o permanencia en él (en comparación con las correspondientes categorías de trabajadores masculinos, o con la población trabajadora en general) no podrían considerarse opuestas al citado principio de igualdad, sino al contrario, dirigidas a eliminar situaciones de discriminación existentes.

90 Díaz, Elías, Estado de derecho y sociedad democrática, Madrid, Taurus 1981, p. 29. 
badas en materia de igualdad de género, paridad democrática, así como en los casos de violencia de género a través de las decisiones jurisdiccionales emitidas por el tribunal constitucional español, pronunciamientos que a su vez han dado mucho para analizar, pero de igual modo, para criticar la labor jurisprudencial del Tribunal respecto a los argumentos expresados en la primera sentencia (59/2008), reiterativos en las posteriores resoluciones jurisdiccionales, sin permitir vislumbrar su línea interpretativa, todo lo contrario, limitándola.

\section{BIBLIOGRAFÍA}

ACALE SÁNCHEZ, María, La discriminación hacia la mujer por razón de sexo en el Código Penal, Madrid, Reus, 2006.

, "Análisis del Código penal en materia de violencia de género contra las mujeres desde una perspectiva transversal", Revista Electrónica del Departamento de Derecho de la Universidad de la Rioja, núm. 7, 2009.

AguAdo Higón, Ana María, "Mujeres y participación política entre la transición y la democracia en España”, Estudios de Derecho Judicial, núm. 142, 2007.

Alarcón CABrera, Carlos, "Reflexiones sobre la igualdad material", Anuario de Filosofia del Derecho, Madrid, nueva época, t. IV, 1987.

Alastuey Dobón, María del Carmen, "Desarrollo parlamentario de la ley integral contra la violencia de género. Consideraciones críticas”, en Rueda Martín, María Ángeles y Boldova Pasamar, Miguel Ángel (coords. ), La reforma penal en torno a la violencia doméstica y de género, Barcelona, Atelier, 2006.

Alfonso SÁnCHEZ, José Manuel y Diestro FERnÁndeZ, Alfonso, La nueva gobernanza. La participación de la mujer en la política de la Unión Europea, Salamanca, Oficina de Promoción Económica y Empleo del Excelentísimo Ayuntamiento de Salamanca, 2005.

AlgAÑARAZ, Juan Carlos, "Nuevo gabinete de Zapatero: por primera vez hay mayoría de mujeres", El Mundo, 13 de abril de 2008.

Álvarez Durante, María Luisa, Coloquio celebrado en el Senado el 11 de marzo de 1994, Las mujeres y el poder político, Madrid, Serie Debate, núm. 16, Ministerio de Asuntos Sociales, Instituto de la Mujer, 2004. Alzaga VillaAmil, Oscar, Comentario sistemático a la Constitución española de 1978, Madrid, Ediciones del Foro, 1979. 
Aquino DE SouZA, Cristiane, "La adopción de medidas con el fin de establecer la Igualdad entre mujeres y hombres en España", Revista Jurídica Universidad Autónoma de Madrid, núm. 21, 2010.

- "Las cuotas electorales y los derechos fundamentales", Universitas. Revista de Filosofía, Derecho y Política, núm. 13, enero de 2011.

ARA Pinilla, I., "Reflexiones sobre el significado del principio constitucional de igualdad", en GARCÍA SAN Miguel, L., El principio de igualdad, Madrid, Dykinson, 2000.

AROZAMENA SiERra, Jerónimo, "Principio de igualdad y derechos fundamentales", en VALDÉS DAL-RE, Fernando, El principio de igualdad en la Constitución española, XI Jornadas de Estudio, Madrid, Ministerio de Justicia, Secretaría General Técnica, 1991, vol. I.

ASÚA BATARRITA, Adela, "La ley de medidas de protección integral contra la violencia de género", Cuadernos Penales José Moría Lidón, núm. 2, Bilbao, Universidad de Deusto, 2005.

AYALA DEL PINO, Cristina, "La igualdad entre mujeres y hombres a las puertas de la futura ley de igualdad en España", en GoNZÁLEZ IBÁÑEZ, Joaquín (coord.), Derechos humanos, relaciones internacionales y globalización, Colombia, Editores Ibáñez, 2006.

BAlaguer CALlejón, María Luisa, "El derecho de igualdad de género: la LO 3/2007, del 22 de marzo, para la Igualdad entre Mujeres y Hombres", en Figueruelo BurrieZA, Ángela et. al. (coords.), Igualdad ¿para qué?: a propósito de la Ley Orgánica para la igualdad efectiva de mujeres y hombres, Granada, Comares, 2007.

BARCELLONA, Pietro, "Estado de derecho, igualdad formal y poder económico: apuntes sobre formalismo y orden económico", Anales de la Cátedra Francisco Suárez, núm. 29, 1989.

BARCElón CoBEDO, Susana y QuinTERo LiMA, María Gema, "El impacto de la Ley para la igualdad en el marco de la normativa de Seguridad Social", Temas Laborales: Revista Andaluza de Trabajo y Bienestar Social, núm. 91, 2007.

BASILE, S., "Los «valores superiores», los principios fundamentales y los derechos y libertades públicas", en PREDIERI, A. y GARCÍA DE ENTERRÍA, E. (eds.), La Constitución española de 1978, Madrid, Civitas, 1980.

BASSO, Lelio, "Giustizia e potere. La lungavia al socialismo", Qualegiusticia, 1971.

Bengoechea GiL, María Angeles, "Acciones positivas y discriminacio- 
nes inversas: dos instrumentos para hacer efectiva la igualdad entre hombres y mujeres", en CRUZ SÁNCHEZ DE LARA, Sorzano (coord.), Mujeres: igualdad y libertad: un homenaje a Enriqueta Chicano, España, Civitas, 2007.

BLÁZQuEZ, J., Igualdad, dignidad y libertad, Navarra, Universidad Pública de Navarra, 1998.

BoBвIO, Norberto, Igualdad y libertad, Barcelona, Paidós, 1993.

BocK, Gisela, La mujer en la historia de Europa, trad. de Lozoya de Teófilo, Barcelona, Crítica, 2001.

Bolea BARDON, Carolina, "En los límites del derecho penal frente a la violencia doméstica y de género", Revista Electrónica de Ciencia Penal y Criminología, núm. 9, 2007.

Bridenthal, Renate y KoOnZ, Claudia, "Mas allá de Kinder, Küche, Kirche: las mujeres de Weimar en la política y en el trabajo", trad. de Eugenio y Marta Portela, en AMELANG, James S. y NASH, Mary (eds.), Historia y género: las mujeres en la Europa moderna y contemporánea, Valencia, Alfons el Magnánim, Institució Valenciana d' Estudis I Investigació, 1990.

CABAllero GEA, José-Alfredo, "Procedimientos contencioso-administrativos: síntesis y ordenación de la doctrina de los tribunales y fiscalía general del estado: actualizado con las formas introducidas por la Ley orgánica 3-2007, 22 de marzo", Igualdad efectiva de mujeres y hombres, Madrid, Dykinson, 2007.

CALSAMIGLiA, Albert, "Sobre el principio de igualdad", en MuguerZA, J. et. al., El fundamento de los derechos humanos, Madrid, Debate, 1989. Castedo Álvarez, F., "La Constitución como fuente de derechos", en ANGUlo Rodríguez, Edmundo et. al., La Constitución española y las fuentes del derecho, Madrid, Dirección General de lo Contencioso del Estado, 1980.

CAstro CID, B., "Derechos humanos y Constitución", Revista de Estudios Políticos, núm. 18, Centro de Estudios Constitucionales, 1980.

CERri, A., Nuove note sul principio di eguaglianza, Giuridica Constitucional, 1971.

— L'eguaglianza nella jurisprudencia della Corte Constituzionale, Milán, 1976.

CERVATI, Ángel Antonio, "El legislador de los derechos fundamentales", en LÓPEZ PINA, Antonio (dir.) et. al., La garantía constitucional de los 
derechos fundamentales. Alemania, España, Francia e Italia, Madrid, Civitas, 1991.

Chacartegui JÁvega, Consuelo, "El largo recorrido hacia igualdad de oportunidades entre hombres y mujeres en el ámbito laboral: un avance significativo con las medidas previstas en la Ley Orgánica de Igualdad", Revista Jurídica de Catalunya, vol. 106, núm. 1, 2007.

Comas de Argemir Cendra, Montserrat, "La Ley Integral contra la Violencia de Género: una ley necesaria", Revista Jurídica de Castilla y León, núm. 4, 2004.

, "El principio de igualdad de oportunidades entre hombres y mujeres en la carrera judicial”, Estudios de derecho judicial, núm. 142, 2007. Del REy GuANTER, S., "La aplicación de los valores superiores de la Constitución española en el derecho del trabajo", La Ley, 1988-I.

DíAZ, Elías, Estado de derecho y sociedad democrática, Madrid, Taurus, 1981.

ELÓSEGUI ITXASO, María, "La estrategia marco comunitaria sobre la igualdad entre hombres y mujeres (2001-2005)", Aequalitas: Revista jurídica de igualdad de oportunidades entre mujeres y hombres, núm. 9, 2002.

_ , "La Ley Orgánica de Igualdad efectiva entre mujeres y hombres. Las acciones positivas para la igualdad laboral entre mujeres y hombres", Cuadernos de Derecho Judicial, núm. 5, 2007.

Figueroa Bello, Aída, "Las recientes directivas comunitarias adoptadas en materia de igualdad de trato entre mujeres y hombres en la Unión Europea”, en LÓPEZ DE LA VIEJA DE LA TORRE, María Teresa (coord.), Bioética y feminismo: estudios multidisciplinares de género, Salamanca, 2006.

Figueruelo BurRIEZA, Ángela, "El discurso jurídico: la mujer en la Constitución española", en FiguerUELO BURRIEZA, Ángela y LóPEZ DE LA VIEJA, Teresa et. al. (eds.), Las mujeres en la Constitución europea. Estudios multidisciplinares de género, Salamanca, Ediciones Universidad de Salamanca-Centro de Estudios de la Mujer, 2005, colección Aquilafuente.

—_, "Setenta y cinco años de sufragio femenino en España. Perspectiva constitucional", Criterio jurídico, núm. 7, 2007.

- "Representación política y democracia paritaria (a propósito de la sentencia del TC 12/2008, del 29 de enero)", Revista Europea de Derechos Fundamentales, núm. 12, 2008. 
- y FreiXes SANJuÁn, Teresa y Remotti CARBonell, José Carlos, "Los valores y principios en la interpretación constitucional", Revista Española de Derecho Constitucional, año 12, núm. 35, mayo-agosto de 1992.

GÁLVEZ MUÑOz, Lina et. al., "La igualdad efectiva entre mujeres y hombres y el bienestar", Temas para el debate, núm. 159, febrero de 2008. GÁlveZ, Javier, “Artículo 14”, en GARrido FAlla, Fernando et. al., Comentarios a la Constitución, Madrid, Civitas, 1985.

GARCÍA DE ENTERRÍA, Enrique, Revolución francesa y administración contemporánea, Madrid, Alianza Editorial, 1994.

- et al., El sistema europeo de protección de los derechos humanos, Madrid, Civitas, 1979.

GARCÍA FERRER, Juan José, "E. Burke: reflexiones sobre la Revolución francesa", en GARCía SAN Miguel RodríGuEZ-ARANGO, Luis, Filosofia politica: las grandes obras, España, Dykinson, 2006

García Morillo, J., "La cláusula general de igualdad", Derecho constitucional. El ordenamiento constitucional. Derechos y deberes de los ciudadanos, Valencia, Tirant lo Blanch, 2000, vol. I.

GARCÍA-NICOLÁS, Cristina, "Igualdad de oportunidades en la Unión Europea y en España”, en FLECHA ANDRÉS, José-Román y GARCÍA-NiCOLÁS, Cristina (coords.), Mujer e igualdad de oportunidades, Salamanca, Universidad Pontificia de Salamanca-Instituto de Estudios Europeos y Derechos Humanos, 2004.

GARRIGUES GIMÉNEZ, Amparo y NúÑEZ-CORTÉS CONTRERAS, Pilar, “(Des) Igualdad en las condiciones de trabajo, incluida la retribución, de los trabajadores con responsabilidades familiares: realidad actual y soluciones - parciales - planteadas en el Anteproyecto de Ley Orgánica de igualdad entre mujeres y hombres (I)", Tribuna Social: Revista de Seguridad Social y Laboral, núm. 192, 2006.

GARRORENA, Ángel, El Estado español como Estado social y democrático de derecho, Tecnos, Madrid, 1987.

GASTÓN ABELLÁN, M., La técnica del precedente y la argumentación racional, Madrid, Tecnos, 1993.

GímENEZ GLUCK, Diego, Una manifestación polémica del principio de igualdad. Acciones positivas moderadas y medidas de discriminación inversa, Valencia, Tirant lo Blanch, 1999.

GONZÁLEZ MARTín, Nuria, "El principio de igualdad y los sistemas de protección de garantías en la Constitución española de 1978: especial 
referencia a la situación jurídica de la mujer", Boletín Mexicano de Derecho Comparado, Nueva Serie, año XXXIV, núm. 102, septiembrediciembre de 2001.

GORDILlO, A., Ley, principios generales y Constitución. Apuntes para una relectura, desde la Constitución, desde la teoría de las fuentes del derecho, Madrid, Centro de Estudios Ramón Areces, 1990.

GuILLÉn SORIA, José Miguel, "Introducción. Violencia doméstica ejercida sobre la mujer. Elementos socio-culturales y económicos que determinan su existencia", en CARRASCO GÓMEZ, Juan José (coord.), Estudios sobre la violencia familiar y agresiones sexuales, Madrid, Ministerio de Justicia-Ministerio de Trabajo y Asuntos Sociales-Instituto de la Mujer, 2000, t. I.

JAÉN VALLEJO, M., "El principio de igualdad en la aplicación de la ley por los órganos jurisdiccionales en la jurisprudencia del TC", Boletín del Colegio de Abogados de Madrid, 1987.

JENSON, Jane y VALIENTE, Celia, "El movimiento a favor de la democracia paritaria en Francia y España", Revista Española de Ciencia Política, núm. 5, 2001.

KRENNERICH, Michael, "Mujeres al parlamento. Sistemas electorales y cuotas de género en la mirilla", en REYNOSO NúÑEZ, José y SÁNCHEZ DE LA BARQUERA Y ARROYO, Herminio (coords.), La democracia en su contexto. Estudios en homenaje a Dieter Nohlen en su septuagésimo aniversario, México, UNAM, Instituto de Investigaciones Jurídicas, 2009.

LAPORTA, Francisco J., "El principio de igualdad. Introducción a su análisis", Sistema, núm. 67, julio de 1985.

, "Problemas de la igualdad", en VALCÁRCEL, Amelia (ed.), El concepto de igualdad, Madrid, Pablo Iglesias, 1994.

Lesmes Zabalegui, Santiago, "Contratación pública y discriminación positiva. Cláusulas sociales para promover la igualdad de oportunidades entre mujeres y hombres en el mercado laboral", Lan Harremanak: Revista de Relaciones Laborales, núm. 13, 2005.

LOMBARDO, Emanuela, "El Mainstreaming: la aplicación de la transversalidad en la Unión Europea", Aequalitas, Revista Jurídica de Igualdad de oportunidades entre mujeres y hombres, núm. 13, 2003.

LÓPEZ RODÓ, Laureano, "El principio de igualdad en la jurisprudencia del Tribunal Constitucional", Revista de Administración Pública, vol. I, núm. 100, Centro de Estudios Constitucionales, enero-diciembre de 1983. 
LÓPEZ, Julia, "Los principios rectores de la LO 3/2007 sobre igualdad efectiva entre mujeres y hombres a la luz de las estrategias de "gender mainstreaming" y "empowerment", Revista del Ministerio de Trabajo e Inmigración, núm. extraordinario, 2007.

LORENTE ACOSTA, Miguel, "Elementos y consideraciones para una solución integral de la violencia de género", en PÉREZ FERnÁndEZ, Miguel et. al., (coords.), Sociedad, violencia y mujer. Retos para afrontar la desigualdad, Salamanca, Amarú, 2005.

LUCAS VERDÚ, Pablo, Estimativa y política constitucionales (los valores y los principios rectores del ordenamiento constitucional español, Madrid, Universidad de Madrid, Facultad de Derecho, 1984.

MAQUEDA ABREU, María Luisa, "La violencia de género: entre el concepto jurídico y la realidad social", Revista Electrónica de Ciencia Penal y Criminología, febrero de 2006.

Martínez Cuadrado, Miguel, "La Constitución de 1978 en la historia del constitucionalismo español”, en MARTínez CUADRADO, Miguel (ed.), La Constitución de 1978 en la historia del constitucionalismo español, Madrid, Mezquita, 1982.

MARTíNEZ-GARCÍA, J. L., "Justicia e igualdad en Luhmann", Anuario de Filosofía del Derecho, núm. 4, 1987.

MARTínez PÉREZ, Álvaro y CAlvo Borobia, Kerman, Un análisis del efecto de la Ley de igualdad en la representación electoral, parlamentaria y en el comportamiento electoral de las mujeres en las elecciones generales de 2008, Madrid, Fundación Alternativas, 2009.

MARTÍNEZ, Jesús Ignacio, "El principio de igualdad y la producción de diferencias en el derecho", El principio de igualdad en la Constitución española, XI Jornadas de Estudio, Madrid, Ministerio de Justicia, Secretaría General Técnica, 1991, vol. I.

MATEOS, Araceli y Ruíz RodRíGUEZ, Leticia M., "Mujer y política en Europa: niveles de participación y representación política femenina en la Unión Europea", en FIgUeruelo BuRriezA, Ángela y LóPEZ DE LA VIEJA, Teresa et. al. (eds.), Las mujeres en la Constitución europea. Estudios multidisciplinares de género, colección Aquilafuente, núm. 87, Salamanca, Ediciones Universidad de Salamanca-Centro de Estudios de la Mujer, 2005.

Mirat Hernández, Carmen Pilar y Armendáriz León, Carmen, Violencia de género versus violencia doméstica, Valencia, Difusión Jurídica y Temas de Actualidad, 2007. 
MONTAlBÁn HUERTAS, Inmaculada, "Ley orgánica 1/2004, del 28 de diciembre, de Medidas de Protección Integral contra la Violencia de Género. Un instrumento normativo novedoso", Cuadernos de Derecho Judicial, núm. 22, 2005.

Moraga GARCíA, Ma. Ángeles, "La igualdad entre mujeres y hombres en la Constitución española de 1978”, Feminismo/s, núm. 8, diciembre de 2006.

Morati, Constantino, Istituzioni di Diritto Pubblico, Padova, 1976.

Murcia ClaVeríA, Ana, "La Ley Orgánica 3/2007, del 22 de marzo, para la igualdad efectiva de mujeres y hombres: un hito legislativo en la consecución de la igualdad real entre mujeres y hombres en el derecho español", Documentación Laboral, núm. 82, 2008.

Murillo DE LA VeGA, Soledad, "La ley de igualdad efectiva entre mujeres y hombres", Estudios de Derecho Judicial, núm. 142, 2007.

MuRILlo DE LA VEGA, Soledad, "Un gesto político frente a la violencia contra las mujeres", Revista de Educación, núm. 342, 2007.

Ollero, A., Igualdad en la aplicación de la ley y precedente judicial, Madrid, Centro de Estudios Constitucionales, 1989.

OÑate Rubalcaba, Pablo y Delgado, Irene, "Partidos, grupos parlamentarios y diputados en las asambleas autonómicas", en OÑATE, Pablo (ed.), Organización y funcionamiento de los parlamentos autonómicos, Valencia, Tirant lo Blanch, 2006.

OrTEGa, Carmen y Trujillo, José M., "Cuotas legales de género y sistemas electorales: las elecciones a Cortes Generales de 2008", Ponencia presentada al X Congreso de la Asociación Española de Ciencia Política y de la Administración, Murcia, 7-9 de septiembre de 2011.

PALAdín, Livio, "Eguaglianza", Enciclopedia di Diritto, Varesse, 1965. , Il principio constituzionaled'eguaglianza, Milán, 1965.

PAPÍ GÁlVEZ, Natalia y ORBEA MiRA, Jesús, "La eficacia publicitaria de las campañas sobre la igualdad de género: análisis de la codificación y del plan de medios", Zer: Revista de Estudios de Comunicación $=$ Komunikazio ikasketen aldizkaria, núm. 30, 2011.

PAREJo Alfonso, Luciano, Constitución y valores del ordenamiento, Madrid, Centro de Estudios Ramón Areces, 1990.

PeCES-BARBA, Gregorio, Los valores superiores, Madrid, Tecnos, 1984. , "Seguridad jurídica y solidaridad como valores de la Constitución española", Funciones y fines del derecho, Murcia, Universidad de 
Murcia, 1992.

PÉREZ CAMPOS, Ana Isabel, "Igualdad y no discriminación en la negociación colectiva", Anuario Jurídico y Económico Escurialense, núm. 43, 2010.

PÉREZ LuÑo, Antonio Enrique, "El concepto de igualdad como fundamento de los derechos económicos, sociales y culturales", Anuario de Derechos Humanos, núm. 1, 1981.

, "Dimensiones de la igualdad material", Anuario de Derechos $\mathrm{Hu}-$ manos, núm. 3, 1984-1985.

, "Sobre la igualdad en la Constitución española", Anuario de Filosofía del Derecho, t. IV, 1987.

, Dimensiones de la igualdad, 2a., ed., Madrid, Dykinson, 2007.

PRIETO, Luis, "La doctrina de los principios generales del derecho y la distinción entre principios y reglas”, en BETEGÓN, J. et. al., Lecciones de teoría del derecho, Madrid, McGraw-Hill, 1977.

__ , "Los valores superiores del ordenamiento jurídico y el Tribunal Constitucional", Poder Judicial, núm. 11, junio de 1984.

PUY, Francisco, "El derecho a la igualdad en la Constitución española", El principio de igualdad en la Constitución española, XI Jornadas de Estudio, Madrid, Ministerio de Justicia, Secretaría General Técnica, 1991, vol. I.

REICHARDT, Rolf y FUSI AIZPURÚA, Juan Pablo, La Revolución francesa y la cultura democrática: la sangre de la libertad, Madrid, Siglo XXI de España, 2002.

REQUEJO, J. L., "Juridicidad, precedente y jurisprudencia”, Revista Española de Derecho Constitucional, núm. 29, mayo-agosto de 1990.

REY MARTínEZ, Fernando, "Cuotas electorales reservadas a mujeres y Constitución”, Aequalitas, Revista Jurídica de Igualdad de Oportunidades entre Mujeres y Hombres, núm. 1, mayo de 1999.

—_, "El derecho fundamental a no ser discriminado por razón de sexo", La discriminación por razón de sexo tras 25 años de la Constitución Española, Madrid, Consejo General del Poder Judicial, 2004.

, Discriminación por razón de género y sistema electoral en Europa y España, México, Tribunal Electoral del Poder Judicial de la Federación, 2009.

Rivas VALleJo, María Pilar, "La Ley Orgánica de igualdad entre mujeres y hombres frente a la violencia de género", Aequalitas: Revista Jurídica de Igualdad de Oportunidades entre Mujeres y Hombres, núm. 20, 2007. 
ROCA TRÍAS, E., "Jurisprudencia, precedente y principio de igualdad", $R e$ vista Jurídica de Cataluña, 1986.

RodríGuez PIÑERO, Miguel y FERnÁndeZ, María Fernanda, Igualdad y discriminación, Madrid, Tecnos, 1986.

RodríGuez-Toubes, J., Principios, fines y derechos fundamentales, Madrid, Dykinson, 2000.

RUBIO DE LA TORRE, José Luis, Ley de violencia de género. Ajuste de constitucionalidad en materia penal, Valencia, Tirant lo Blanch, 2007.

RuBio Llorente, Francisco, "La igualdad en la jurisprudencia del Tribunal Constitucional. Introducción", El principio de igualdad en la Constitución española, XI Jornadas de Estudio, Madrid, Ministerio de Justicia, Secretaría General Técnica, 1991, vol. I.

, "Igualdad", en ARAGÓN REYES, Manuel (coord.), Temas básicos de derecho constitucional, Madrid, Civitas, 2001, t. III.

et. al., Derechos fundamentales y principios constitucionales.

Doctrina jurisprudencial, Barcelona, Ariel, 1995.

Ruíz Miguel, Alfonso, "Discriminación inversa e igualdad", en VALCÁRCEL, Amelia (comp.), El concepto de igualdad, Madrid, Pablo Iglesias, 1994.

, "Ciudadanía y derechos de las mujeres: un largo camino abierto", en GONZÁLEZ RuIZ, Pilar et. al., El movimiento feminista en España en los años setenta, Valencia, Cátedra Universitat de València, 2009.

Ruíz VADILlO, Enrique, "El principio de igualdad en la Constitución española", El principio de igualdad en la Constitución española, XI Jornadas de Estudio, Madrid, Ministerio de Justicia, Secretaría General Técnica, 1991, vol. I.

SÁNCHEZ DíEZ, Ingrid Estibaliz, "La participación de la mujer en política”, en Martínez Gallego, Eva María y Reguero CeladA, Justo (coords.), Mujer y empleo. Una estrategia para la igualdad, Granada, Comares, Colección Trabajo y Seguridad Social, núm. 18, 2004.

SÁNCHEZ GonZÁlEZ, Santiago, "En torno a la igualdad y a la desigualdad”, en SAnchÉz GonzÁlez, Santiago (coord.), En torno a la igualdad y a la desigualdad, Madrid, Dykinson, 2009.

SÁNCHEZ MORÓN, Miguel, "El principio de participación en la Constitución española", Revista de Administración Pública, núm. 89, mayoagosto de 1979.

SANMARTín, Olga R., "El 80\% de las sentencias de violencia de género 
condena al agresor", El Mundo, 10 de febrero de 2010, en http://www. elmundo.es/elmundo/2010/02/09/espana/1265719274.html.

SERRA CRISTÓBAL, Rosario, "La presencia de las mujeres en los parlamentos autonómicos. La efectividad de las medidas adoptadas por los partidos políticos y por el legislador", Revista de Estudios Políticos, núm. 141, 2008.

y OÑATE, Pablo, "La presencia de la mujer en los parlamentos en España: cantidad y calidad de la paridad", VII Congreso Mundial de la Asociación Internacional de Derecho Constitucional 6-10 de diciembre de 2010, Madrid, 2010.

Sevilla, Julia, Sobre principios y normas. Problemas del razonamiento jurídico, Madrid, Centro de Estudios Constitucionales, 1992.

, "Género y Estado", en CAMPILlo IBORRA, Neus (coord.), Género, ciudadanía y sujeto político. En torno a las políticas de igualdad, Valencia, Institut Universitari d'Estudis de la Dona-Universitat de València, 2010.

STRAUSS, David A., "The Illusory Distinction between Equality of Opportunity and Equality of Result", William and Mary Law Review, vol. 34, núm. 171, 1992 y 1993.

SúArez Pertierra, Gustavo, “Artículo 14”, en Alzaga Villamil, Oscar (dir.), Comentarios a las Leyes Políticas. Constitución Española de 1978, Editorial Revista de Derecho Privado, 1984, t. II.

SUAY-RINCÓN, José, El principio de igualdad en la justicia constitucional, Madrid, Instituto de Estudios de Administración Local, 1985.

Threfall, Monica, "Explaning Gender Parity Representation in Spain: The Internal Dynamics of Parties", West European Politics, Issue 5, 2007.

Tobío SOler, Constanza y Fernández Cordón, Juan Antonio, "Conciliar las responsabilidades familiares y laborales: políticas y prácticas sociales", Documentos de trabajo (Laboratorio de alternativas), núm. 79, 2005.

Tocino, Isabel, Por una democracia paritaria, Madrid, Instituto de la Mujer, 2004.

UBEDA DE TORRES, Amaya, "La política de empleo de la UE y la igualdad entre hombres y mujeres: un desafío al futuro de Europa", Revista de Derecho Comunitario Europeo, año 7, núm. 15, 2003.

VARELA, Santiago, "La Constitución española en el marco del derecho constitucional comparado”, en FERNÁNDEZ RoDRíGUEZ, Tomás R. (coord.), 
Lecturas sobre la Constitución española, Madrid, Universidad Nacional de Educación a Distancia, 1978, t. I.

Verge Mestre, Tảnia, "Mujer y partidos políticos en España: las estrategias de los partidos y su impacto institucional, 1978-2004", Revista Española de Investigaciones Sociológicas, núm. 115, 2006.

__ "Mujer y partido político en España. Las estrategias de los partidos y su impacto institucional", Revista Española de Investigaciones Sociológicas, núm. 115, 2007.

__ "Cuotas voluntarias y legales en España. La paridad a examen", Revista Española de Investigaciones Sociológicas, núm. 123, 2008.

VILlACAMPE AstlaRTE, Carmen, "El maltratado singular cualificado por razón de género: debate acerca de su constitucionalidad", Revista Electrónica de Ciencia Penal y Criminología, núm. 9-12, 2007.

VillacorTa MANCEBO, Luis, El principio de igualdad y Estado social. Apuntes para una relación sistemática, Cantabria, Parlamento de Cantabria-Universidad de Cantabria, 2006.

Westen, P., "The Empty Idea of Equality", Harvard Law Review, núm. 95, 1982.

\section{Legislación}

Ley 3/1989, del 3 de marzo, por la que se amplía a dieciséis semanas el permiso por maternidad y se establecen medidas para favorecer la igualdad de trato de la mujer en el trabajo.

Ley 39/1999, del 5 de noviembre, para promover la conciliación de la vida familiar y laboral de las personas trabajadoras.

Ley 51/2003, del 2 de diciembre, de igualdad de oportunidades, no discriminación y accesibilidad universal de las personas con discapacidad.

Ley13/1982, del 7 de abril, relativa a la integración social de los minusválidos.

Ley 16/1983, del 24 de octubre, de creación del organismo autónomo Instituto de la Mujer.

Ley 01/2004, del 28 de diciembre, de Medidas de Protección Integral contra la Violencia de Género.

Ley Orgánica 3/2007, del 22 de marzo para la igualdad efectiva de Mujeres y Hombres. 
2. Fuentes jurisprudenciales

Sentencia TC 22/81, del 2 de julio.

Sentencia TC 42/81, del 22 de diciembre.

Sentencia TC 49/82, de 14 de julio.

Sentencia TC 49/82, del 14 de julio.

Sentencia TC 75/83, del 3 de agosto.

Sentencia TC 31/84, del 7 de marzo.

Sentencia TC 78/84, del 9 de julio.

Sentencia TC 98/85, del 29 de julio.

Sentencia TC 128/87, del 16 de julio.

Sentencia TC 142/85, del 23 de octubre.

Sentencia TC 59/2008, del 14 de mayo.

Sentencia TC 76/2008, del 3 de julio.

Sentencia TC 81, 82 y 83/2008, del 17 de julio.

Sentencia TC 95, 96, 97, 98, 99 y 100/2008, del 24 de julio.

Sentencia TC 45/2009, del 19 de febrero.

Fecha de recepción: 14 de marzo de 2011.

Fecha de dictamen: 25 de abril de 2011. 